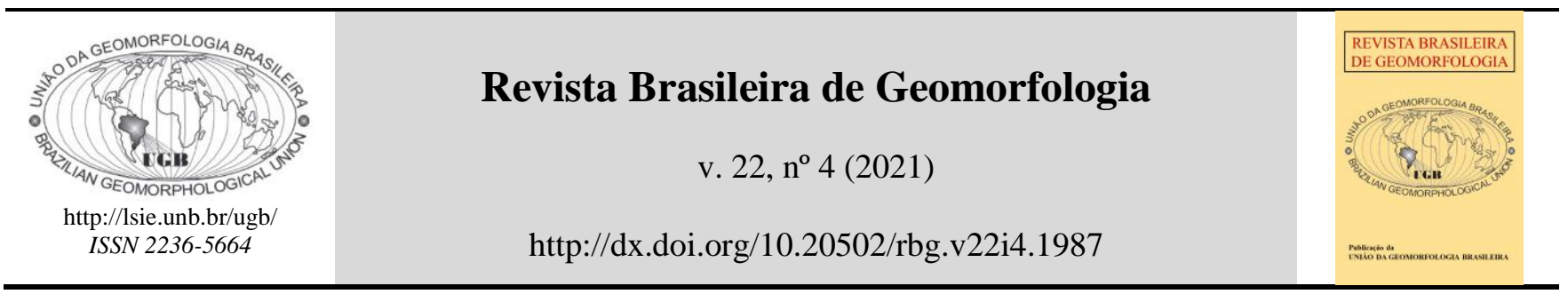

Artigo de Pesquisa

\title{
Emprego de segmentação multiresolucional no mapeamento digital de formas de relevo
}

Multiresolution segmentation applied in digital mapping of landforms

\section{Willian Bortolini' ${ }^{1}$, Claudinei Taborda da Silveira ${ }^{2}$}

1 Universidade Federal do Paraná, Programa de Pós-Graduação em Geografia, Curitiba, Brasil. willianbortolini@gmail.com ORCID: http://orcid.org/0000-0002-1164-1239

2 Universidade Federal do Paraná, Departamento de Geografia e Programa de Pós-Graduação em Geografia, Curitiba, Brasil. claudineits@ufpr.br

ORCID: http://orcid.org/0000-0001-6289-6306

Recebido: 20/07/2020; Aceito: 29/03/2021; Publicado: 01/10/2021

Resumo: As técnicas geomorfométricas, baseadas na análise orientada a objeto e que empregam o algoritmo de segmentação multiresolucional, apresentam potencialidade de aplicação no mapeamento digital do relevo. O artigo teve como objetivo demonstrar a classificação semiautomatizada de padrões de formas de relevo com o emprego de segmentação multiresolucional. Foram calculados de um MDT os parâmetros: declividade, relevo sombreado, índice de posição topográfico, amplitude altimétrica, média da declividade e média do índice de densidade de rupturas de declive, seguido da execução de seis etapas de segmentação e classificação: a primeira classificou as planícies fluviais; as duas próximas classificaram as áreas por nível de dissecação (baixa, média e alta) e as demais classificaram os padrões pertencentes a cada níveis. Os resultados obtidos foram doze padrões de formas de relevo: 1) planícies fluviais, 2) colinas, 3) colinas onduladas, 4) morrotes do tipo I, 5) morrotes do tipo II, 6) morros do tipo I, 7) morros do tipo II, 8) morros declivosos do tipo I, 9) morros declivosos do tipo II, 10) morros declivosos do tipo III, 11) morros elevados do tipo I e 12) morros elevados do tipo II, que apresentaram acerto de $77 \%$, verificados a partir de 155 observações realizadas em campo.

Palavras-chave: Algoritmo de segmentação multiresolucional. Mapeamento Digital de formas de relevo. Geomorfometria. Análise orientada a objeto.

\begin{abstract}
Geomorphometric techniques, based on object-oriented analysis and employing the multiresolutional segmentation algorithm have the potential to be applied in digital mapping of landforms. The aims of this paper was to demonstrate a semiautomated technique based on the use of multiresolutional segmentation for the classification of patterns of landforms. The parameters were calculated from a DTM: slope, shaded relief, topographic position index (TPI), altimetric amplitude, mean slope and mean edge density, followed by the execution of six stages of segmentation and classification: the first stage classified the river plains; the next two stages classified the areas from level of dissection (low, medium and high) and the other stages classified the patterns of relief forms belonging to each of these levels. The results obtained were 12 patterns of landforms: 1) river plains, 2) low hills, 3) undulated low hills, 4) type I hillocks, 5) type II hillocks, 6) type I hills, 7) type II hills, 8) type I steep hills, 9) type II steep hills, 10) type III steep hills, 11) type I high hills, and 12) type II high hills. The results showed $77 \%$ correctness, verified from 155 observations made in the field.
\end{abstract}

Keywords: Multiresolutional segmentation algorithm. Digital mapping of landforms. Geomorphometry. Object based analysis. 


\section{Introdução}

A abordagem geomorfométrica tem ganhado destaque a partir da década de 1970 por meio do desenvolvimento da informática, das geotecnologias e dos modelos digitais de elevação (MDEs), que possibilitaram sua aplicação em ambiente digital (WOOD, 1996; PIKE, 2000; PIKE; EVANS; HENGL, 2009). Ela tem como foco a extração de mensurações (parâmetros ou atributos topográficos) e feições espaciais (objetos ou formas de relevo) a partir dos dados dos MDEs (WILSON, 2012) e vem sendo empregada na classificação digital do relevo desde o final da década de 1980 (HENGL; MACMILLAN, 2009).

A maioria das técnicas de classificação digital do relevo é orientada ao pixel, ou seja, consistem na classificação de pixels individualizados e que em seguida são agrupados, definindo-se assim a extensão das formas de relevo (DRAGUT; EISANK, 2011). Entretanto, outras destas técnicas são baseadas na classificação orientada a objeto. Neste tipo de classificação, grupos de pixels adjacentes e que apresentam relativa homogeneidade são agregados, criando assim objetos de imagem que em seguida são classificados (DRAGUT; BLASCHKE, 2006).

As aplicações de técnicas de classificação orientada a objeto na análise da paisagem apresentam potencialidades como a generalização da classificação, evitando assim a classificação de pixels isolados (WILLHAUCK, 2000) e a possibilidade da utilização de regras de classificação baseadas nas relações topológicas entre objetos (ANDERS; SEIJMONSBERGEN; BOUTEN, 2011). Bishop et al. (2012, p. 20) afirmam que as classificações orientadas a objeto possibilitam a "integração das informações, a caracterização de contexto e topologia, e a vinculação de recursos em várias escalas". Além disso, os objetos de imagem fornecem mais informações do que um pixel individualizado, cujas informações podem ser utilizadas em análises estatísticas ou em classificações de dados matriciais (BENZ et al., 2004; ASSELEN; SEIJMONSBERGEN, 2006).

Neste trabalho, é empregado o algoritmo de segmentação multiresolucional de Baatz e Schape (2000). Este algoritmo é uma técnica Bottom-Up baseada na combinação de procedimentos de crescimento de regiões e detecção de bordas, que se inicia a partir de objetos de imagem compostos por um pixel. Em sucessíveis níveis, os objetos de imagem menores são fusionados aos objetos de imagem adjacentes mais semelhantes, compondo objetos de imagem maiores. Para cada nível executado, a semelhança de cada dupla de objetos de imagem adjacentes é analisada, verificando quais são mais semelhantes e se é possível a fusão entre eles. Este procedimento se repete nos sucessíveis níveis, até que não haja mais possibilidades de fusões entre nenhuma dupla de objetos de imagem adjacentes, encerrando assim o processo de segmentação (BAATZ, SCHAPE, 2000; BENZ et al., 2004).

A decisão sobre a fusão é baseada na diferença de heterogeneidade entre dois objetos de imagem adjacentes, sendo que o critério entre eles é pela mudança de heterogeneidade após uma fusão virtual (BAATZ; SCHAPE, 2000; ANTUNES, 2003). O critério de fusão é dado pela soma ponderada de outros dois critérios, a heterogeneidade espectral (cor) e a heterogeneidade espacial (forma), que por sua vez é composta por dois subcritérios, compacidade e suavidade (ANTUNES, 2003; BENZ et al., 2004). Os objetos de imagem adjacentes que apresentarem o menor valor para o critério de fusão irão se fundir, sendo que este procedimento de fusão entre objetos e imagem e a criação de novos objetos maiores se sucederá até que não seja mais possível se realizarem fusões. Isso ocorre quando o critério de fusão calculado para todas as possíveis fusões virtuais excede o limiar dado pelo fator de escala (BENZ et al., 2004), que é um parâmetro adimensional, que especifica o nível de homogeneidade dos objetos de imagem a serem criados (EISANK; SMITH; HILLIER, 2014). Esse é o parâmetro que controla o tamanho médio dos objetos de imagem segmentados (BAATZ; SCHAPE, 2000).

Quando se trata de classificações orientadas a objeto, o trabalho com as hierarquias espaciais é um ponto relevante. As hierarquias espaciais estão associadas ao tamanho dos objetos de imagem e consequentemente a escala, e para poder lidar com elas, utiliza-se de algoritmos de segmentação multinível ou multiescala (STROBL, 2008). Este é o caso do algoritmo de segmentação multiresolucional, pois ele permite a construção de uma rede Revista Brasileira de Geomorfologia. 2021, v. 22, n. 4; (Out-Dez) DOI: 10.20502/rbg.v22i4.1987 
hierárquica a partir da segmentação em vários níveis. Nessa rede hierárquica, os limites dos objetos de imagem devem seguir os limites dos objetos segmentados no nível hierárquico superior, cuja segmentação é restrita apenas aos limites dos objetos que foram segmentados no nível hierárquico superior. Por meio dessa abordagem hierárquica, é possível classificar de várias estruturas de distintas escalas, além da segmentação de diferentes níveis hierárquicos a partir de diferentes dados de entrada, e por fim, a correção da forma do objeto por meio do reagrupamento de sub-objetos (BENZ et al., 2004).

Conforme Antonio (2013), na análise orientada a objeto, quando se trabalha com o princípio da segmentação hierárquica, é utilizada, principalmente, as abordagens Top-down e Bottom-up para a criação de objetos de imagem. A primeira, Top-down, parte da segmentação de objetos de imagem maiores que são posteriormente subdivididos em objetos de imagem mais detalhados. É importante ressaltar que nesta abordagem os objetos segmentados nos níveis hierárquicos inferiores respeitam os limites dos objetos segmentados nos níveis superiores. A segunda, Bottom-up, parte da segmentação de objetos de imagem de maior detalhe, que são posteriormente agregados para formar os níveis hierárquicos seguintes, os objetos de imagem maiores.

O modo de classificação Top-down é o mais comumente empregado na representação geomorfológica, em especial quando utiliza a abordagem hierarquizada em níveis de escala. No Brasil a organização hierárquica mais comum na representação da cartografia geomorfológica é em níveis taxonômicos, contido nas propostas de IBGE (2009), Ross (1992) e Ross e Moroz (1997), Oka-Fiori et al. (2006) e Santos et al. (2006). Por isso, esse foi o modo de classificação adotado no presente experimento.

Quando aplicado na delimitação de unidades de terreno e comparado a outros dois algoritmos, a segmentação multiresolucional apresentou como resultados "componentes do terreno relativamente homogêneos" e teve o melhor desempenho na deteç̧ão das descontinuidades morfológicas (VAN NIERKERK, 2010, p. 943). A segmentação multiresolucional tem sido empregada com sucesso na análise de MDE e classificação de formas de relevo (DRAGUT; EISANK, 2011). Os trabalhos pioneiros de Dragut e Blaschke (2006) e Asselen e Seijmonsbergen (2006), classificaram tipos de elementos de forma de relevo e unidades geomorfológicas, respectivamente, com o uso desse algoritmo. Na sequência, outros trabalhos empregaram segmentação multiresolucional para classificarem formas de relevo nas mais diversas escalas, partindo de uma escala em nível global (DRAGUT; EISANK, 2012; DEKAVALLA; ARGIALAS; 2017), em escala intermediária (CAMARGO et al., 2009) e até formas de relevo em escala de detalhe (ANDERS; SEIJMONSBERGEN; BOUTEN, 2011; GERÇEK; TOPRAK; STROBL, 2011; VERHAGEN; DRAGUT, 2012; ANDERS; SEIJMONSBERGEN; BOUTEN, 2013; D'OLEIRE-OLTMANNS ; EISANK; BLASCHKE, 2013; TEDESCO; ANTUNES; OLIANI, 2014).

Camargo et al. (2009) e Dragut e Eisank (2012) empregaram a análise multiescalar do relevo, apresentando hierarquias entre níveis ou táxons geomorfológicos no mapeamento das formas de relevo. Dragut e Blaschke (2006), Asselen e Seijmonsbergen (2006) e Dekavalla e Argialas (2017), por sua vez, empregam a classificação hierárquica objetivando mapear formas de relevo em uma mesma escala geomorfológica. Já Anders, Seijmonsbergen e Bouten (2011) e Anders, Seijmonsbergen e Bouten (2013), além de empregar abordagem semelhante, ainda fizeram uso de critérios de segmentação específicos para diferentes formas de relevo a serem classificadas.

Nesse contexto, o emprego de segmentação multiresolucional se mostra como opção viável ao mapeamento digital semiautomatizado de formas de relevo, o que conduz ao objetivo dessa pesquisa, que é de desenvolver e avaliar uma técnica geomorfométrica baseada no uso de segmentação multiresolucional para o mapeamento de padrões de formas de relevo. 


\section{2. Área de Estudo}

Foi adota a carta Curitiba (MI 2842), na escala 1:100.000, localizada na porção leste do estado do Paraná, cuja área é de $2.709 \mathrm{~km}^{2}$ para realizar o experimento. A justificativa do recorte geográfica para demonstrar a potencialidade do método foi em razão de que ela se configura como uma região com diversidade de formas de relevo.

A área de estudo está localizada no chamado Escudo Paranaense, composta por 18 as unidades geológicas (Figura 1), conforme Mineropar (2001). Os litotipos presentes são rochas cristalinas do Complexo Gnáissico Migmatítico, do Complexo Metamórfico Indiferenciado e do Complexo Granítico Gnáissico (MINEROPAR, 2001); rochas metassedimentares da Formação Perau e da Formação Água Clara, pertencentes ao Grupo Setuva (MINEROPAR, 2001; OLIVEIRA et al., 2002); rochas metassedimentares do Grupo Açungui, das formações Capiru, composta predominantemente por metadolomitos, filitos e quartzitos (MINEROPAR, 2001; ROSA FILHO; GUARDA, 2008); Votuverava, que consiste, predominantemente, de metapelitos rítmicos (FIORI; GASPAR, 1993; FALEIROS, 2008); Antinha, composta por um pacote de metassedimentos clásticos (FIORI, 1992; FIORI; GASPAR, 1993); os blocos graníticos como o Granito Anhangava (KAUL, 1997), o Granito Cerne, o Granito Rio Abaixo, o Granito Pula Sapo, o Granito Piedade e o Granito Taici e o Granito Três Córregos (MINEROPAR, 2001) e materiais sedimentares da Bacia de Curitiba (MINEROPAR, 2001), composta pela Formação Guabirotuba e os Depósitos Aluvionares Holocênicos (SALAMUNI; SALAMUNI; EBERT, 1999; SALAMUNI et al., 2013).

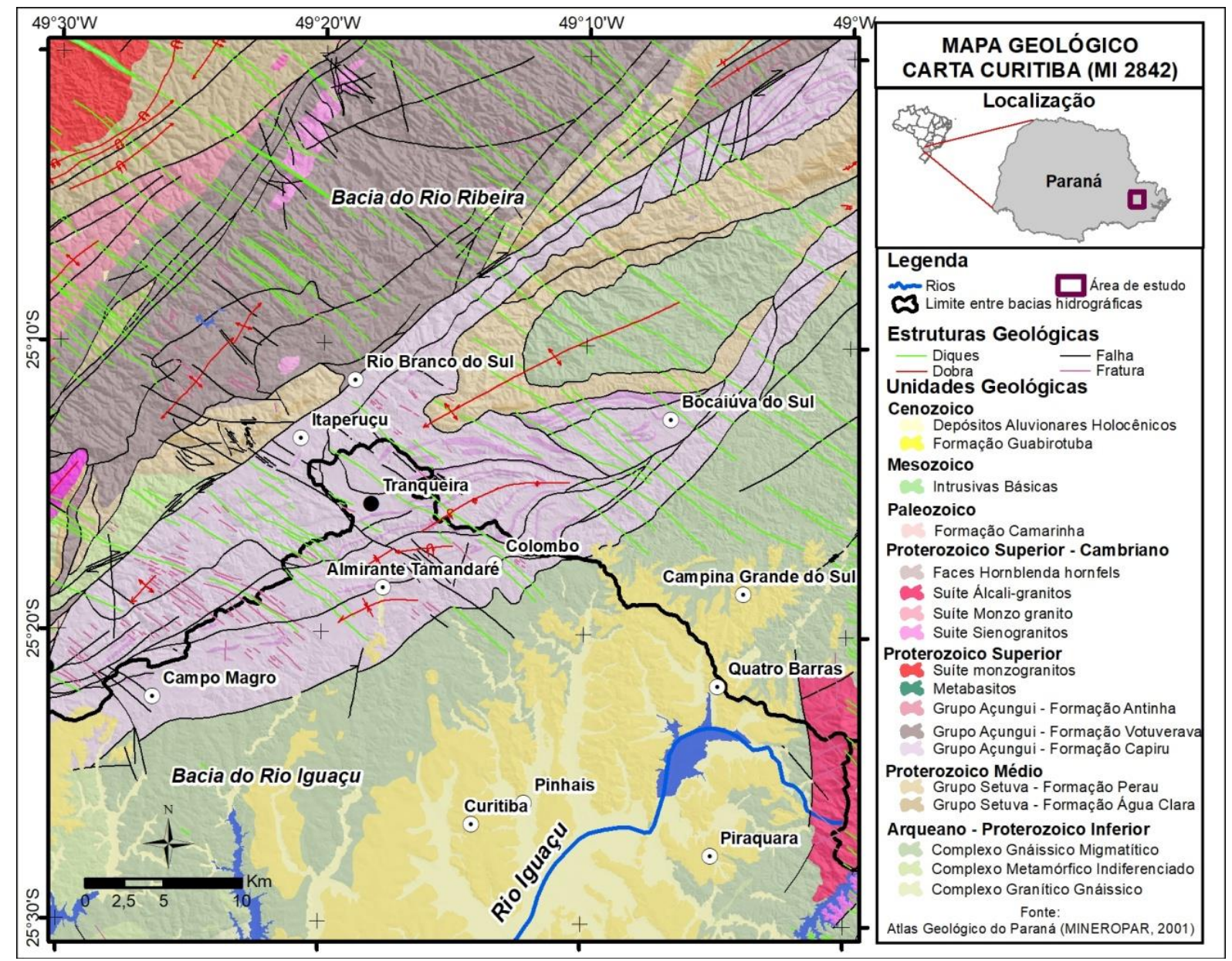

Figura 1. Mapa geológico da área de estudo. Fonte: adaptado de Mineropar (2001). 
Quanto às estruturas geológicas, a Carta Curitiba é caracterizada pela presença de diques e fraturas dispostas paralelamente e com orientação na direção geral NW-SE, que estão ligados aos movimentos orogênicos positivos relacionados ao Arco de Ponta Grossa (FIORI, 1992). O enxame de diques do Arco de Ponta Grossa, predominantemente basálticos, constitui uma notável feição geológica com alinhamentos estruturais de direção preferencial entre N50W e N60W, cuja extensão pode variar de alguns metros a dezenas de quilômetros (RENNE et al. 1996). Outras estruturas geológicas que se destacam na área de estudo são as falhas orientadas, cuja direção geral é NE-SW, associadas ao Sistema Transcorrente da Lancinha (FIORI, 1992).

Em relação aos aspectos geomorfológicos, conforme o atlas geomorfológico do estado do Paraná (OKA-FIORI et al., 2006) (Figura 2), a área de estudo está situada no chamado Primeiro Planalto Paranaense e, em uma menor porção, nas "Planícies, que compreendem sete subunidades morfoesculturais (OKA-FIORI et al., 2006; SANTOS et al.; 2006). Em uma escala mais detalhada, Bortolini et al. (2018) identificaram um predomínio de padrões de formas de relevo mais dissecados na área da bacia do rio Ribeira-Iguape, em relação à bacia do rio Iguaçu, na qual predomina padrões de formas de relevo menos dissecadas.

Em relação à morfogênese, no mapeamento do Projeto RadamBrasil (COSTA; BUSS; ROSA, 1983), são identificadas áreas agradacionais, como a planície do rio Iguaçu, e áreas de dissecação homogênea ou estrutural. As áreas com gênese estruturais estão localizadas na porção norte-noroeste da carta, e estão associadas à presença do enxame de diques de diabásio na direção NW-SE (COSTA; BUSS; ROSA, 1983), além de áreas controladas pelo litotipo, como relevos orientados na direção NE-SW, controlados pelos quartzitos da Formação Capiru (ROSA FILHO; GUARDA, 2008; SALAMUNI et al., 2013), e os relevos residuais do Granito Anhangava (COSTA; BUSS; ROSA, 1983).

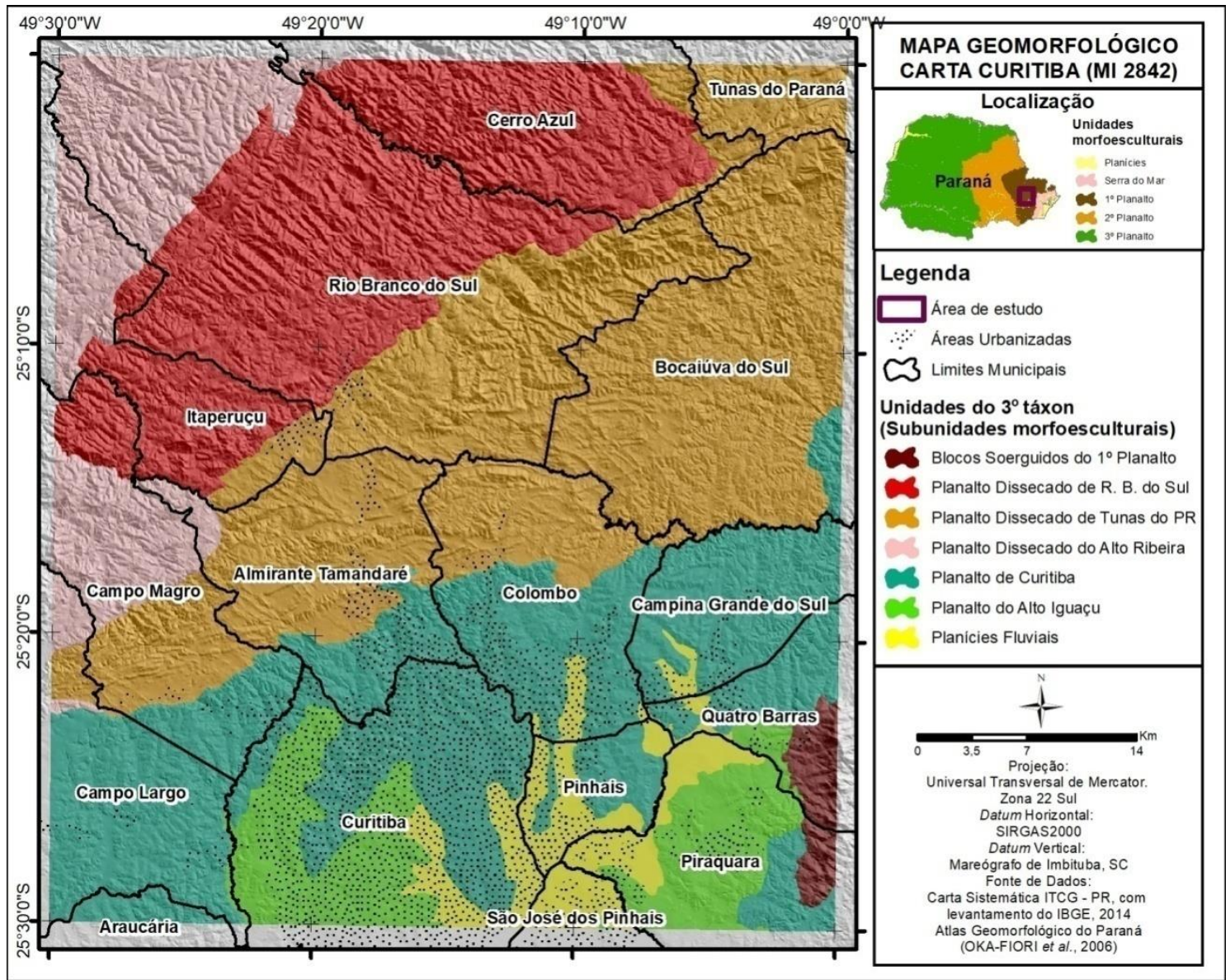

Figura 2. Mapa geomorfológico da área de estudo. 


\section{Materiais e Métodos}

As etapas operacionais desta pesquisa foram organizadas em cinco fases, representadas no fluxograma metodológico na Figura 3.

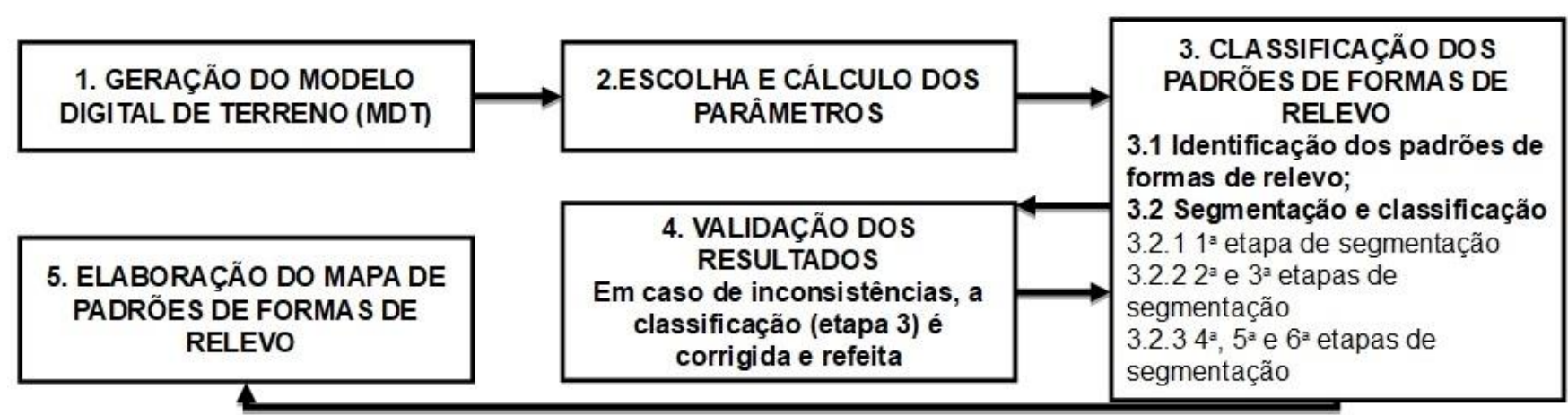

Figura 3. Fluxograma metodológico.

Os cálculos dos parâmetros foram realizados nos softwares ArcGIS 10.1 (ESRI), SAGA GIS 2.3.2 (CONRAD et al., 2015) e WhiteBox Tools (v.0.16.0) (LINDSAY, 2016), através da interface do WhiteBox Runner (LINDSAY, 2019), enquanto a classificação dos padrões de formas de relevo foi realizada no software eCognition Developer 8.8 (TRIMBLE). Por fim, a elaboração da representação gráfica do mapa de padrões de formas de relevo foi realizada no software ArcGIS 10.1 (ESRI).

\subsection{Geração do $M D T$}

O MDT utilizado foi gerado pela aplicação do algoritmo ANUDEM, (HUTCHINSON, 1989), que é hidrologicamente consistente, a partir de dados planialtimétricos vetoriais (curvas de nível, pontos cotados e hidrografia) extraídos de cartas topográficas disponibilizadas pelo IBGE e pelo Departamento de Serviço Geográfico (DSG), na escala 1:50.000. A rede hidrográfica foi submetida à edição topológica do sentido do fluxo e sua utilização no modelo teve objetivo de melhorar o ajuste dos fundos de vale. A resolução espacial do modelo é de 20m, que foi calculado por meio do método de complexidade do relevo (HENGL, 2006), que leva em consideração o comprimento das curvas de nível e a área do modelo.

\subsection{Escolha e cálculo dos parâmetros}

Foram escolhidos e calculados seis parâmetros do MDT: amplitude altimétrica, declividade, média da declividade, IPT relevo sombreado e média do índice de densidade de rupturas. Os quatro primeiros foram adotados por se tratarem daqueles que vem sendo utilizados em trabalhos prévios de mapeamento digital dos padrões de formas de relevo (BORTOLINI; SILVEIRA; SILVEIRA, 2017; BORTOLINI et al.; 2018; GOMES; SILVEIRA; SILVEIRA, 2018; SILVEIRA et al., inédito). O relevo sombreado foi escolhido por demonstrar potencial na detecção de padrões de formas semelhantes, visto que de modo visual sua interpretação já é empregada na distinção e mapeamento de unidades de relevo (SANTOS et al., 2006). Segundo Olaya (2009) os mapas de relevo sombreado podem ser usados para alterar a representação de outras imagens, contendo diferentes parâmetros de diferentes tipos de informação, este efeito é obtido usando o relevo sombreado e modificando o brilho dos pixels. Apoiado nessa premissa, seu emprego foi incorporado na segmentação multiresolucional, adaptação semelhante foi realizada por Camargo et al. (2009) na segmentação de unidades geomorfológicas detalhadas. A média do índice de densidade de rupturas foi escolhida por representar informações de uma característica morfográfica distinta em relação aos demais parâmetros considerados.

- Amplitude altimétrica, que se caracteriza como a diferença entre o valor máximo e mínimo da elevação, calculada na área de entorno da célula considerando um raio de análise de vizinhança circular, cujo valor adotado correspondente ao valor da moda do comprimento das vertentes da área de estudo, seguindo a mesma lógica 
utilizada por Bortolini, Silveira e Silveira (2017), Bortolini et al. (2018) e Gomes, Silveira e Silveira (2018). A amplitude altimétrica foi calculada com quatro raios distintos: 300, 400, 500 e 600m. O cálculo com distintos valores de raios se deu devido ao fato desta proposta metodológica empregar a lógica multiresolucional, na qual cada nível hierárquico da classificação pode utilizar diferentes dados de entrada, como é evidenciado na etapa operacional seguinte.

- Declividade, que indica a inclinação de um pixel em relação ao seu entorno, sendo calculada a partir de uma janela móvel 3x3 pixels, conforme as variáveis direcionais do modelo teórico de Horn (1981).

- Média da declividade, é caracterizada como o valor médio da declividade na janela circular móvel de vizinhança, cujos raios empregados foram os mesmos do cálculo da amplitude altimétrica. Portanto, foram calculadas quatro médias da declividade de raios de 300, 400, 500 e 600 metros.

- Índice de posição topográfica (IPT), proposto por Weiss (2001) e derivado do cálculo de diferença da elevação média de Wilson e Gallant (2000), representa a diferença entre a elevação do pixel central $\left(Z_{0}\right)$ com a média de elevação (Z), calculada na janela circular de vizinhança (Eq. 1). O valor do raio foi de $1000 \mathrm{~m}$, baseado em testes de tentativa e erro. Esse índice expressa quanto um relevo está mais elevado, ou menos elevado, em relação ao seu entorno.

$$
I P T=Z_{0}-Z
$$

- Relevo sombreado, simula a iluminação a partir de determinados ângulos de azimute e altitude sobre um MDT, sendo calculado a partir de uma janela $3 \times 3$ pixels, conforme as variáveis direcionais do modelo teórico de Horn (1981). Foram gerados relevos sombreados a partir de um ângulo de elevação solar moderado de $45^{\circ}$ com combinações de azimute $45^{\circ}$ e $315^{\circ}$, devido ao fato de representarem as duas orientações mais marcantes do relevo da área, NWSE e NE-SW, respectivamente, que são perpendiculares às principais estruturas geológicas presentes.

- Média do índice de densidade de rupturas de declive (M-IDRD), que é calculado a partir do índice densidade de rupturas (IDRD) (LINDSAY, 2019), disponível na plataforma WhiteBox Tools, desenvolvido pelo Geomorphometry $\mathcal{E}$ Hydrogeomatics Reserch Group da Universidade de Guelph, Canadá. Este índice consiste no cálculo da proporção de pixels que se caracterizam como rupturas de relevo em um dado raio de análise de vizinhança. É considerado como ruptura de relevo um pixel que possui uma dada diferença angular de declividade em relação aos seus vizinhos. O valor adotado para a diferença angular foi de $12^{\circ}$, ou $22 \%$, que corresponde a média da declividade da área de estudo. Quanto ao raio de análise de vizinhança, foi empregada a mesma lógica e valores utilizados no cálculo da amplitude altimétrica e da média da declividade. Na sequência, foi aplicado um filtro de média, com o mesmo valor de raio empregado anteriormente, cujo objetivo foi de reduzir os ruídos e homogeneizar os valores da densidade de rupturas nas áreas compostas pela sequência de duas vertentes, (que correspondem a uma forma de relevo individualizada, que resultou no parâmetro topográfico média do índice de densidade de rupturas de declive.

\subsection{Classificação dos padrões de formas de relevo}

O procedimento de classificação dos padrões de formas de relevo foi realizado em quatro níveis hierárquicos, por meio de seis etapas de segmentação/classificação, a partir da abordagem Bottom-up. A nomenclatura dos padrões de relevo e suas respectivas regras de classificação foram definidas a partir da adaptação da classificação empregada por Bortolini et al. (2018) e Silveira et al. (inédito), além do auxílio de 33 pontos de controle obtidos em campanhas de campo prévios.

a) A primeira etapa (1 nível hierárquico) foi responsável pela segmentação de toda a área, que gerou objetos de imagem que foram classificados como "planícies fluviais" ou "áreas não classificadas".

b) Na segunda etapa ( $2^{\circ}$ nível hierárquico) as "áreas não classificadas" foram segmentadas, resultando assim em objetos de imagem que foram classificados como "baixa dissecação" ou "áreas não classificadas". 
c) Na terceira etapa (3॰ nível hierárquico) as "áreas não classificadas", fruto do processo de classificação da segunda etapa, foram segmentadas e geraram novos objetos de imagem que foram então classificados como "média dissecação" ou "alta dissecação".

d) Na quarta etapa (4 nível hierárquico) a área classificada como "baixa dissecação" foi segmentada, resultando em objetos de imagem que foram classificados como "colinas", "colinas onduladas", "morrotes do tipo I" ou "morrotes do tipo II".

e) Na quinta etapa (4 nível hierárquico), a área classificada como "média dissecação" foi segmentada, resultando em objetos de imagem que foram classificados como "morros do tipo I", "morros do tipo II", "morros declivosos do tipo I", "morros declivosos do tipo II" ou "morros declivosos do tipo III".

f) Na sexta etapa (4 nível hierárquico) a área classificada como "alta dissecação" foi segmentada, resultando em objetos de imagem que foram classificados em "morros elevados do tipo I" ou "morros elevados do tipo II".

A organização hierárquica das etapas de segmentação/classificação é exibida no fluxograma da Figura 4. Todos os procedimentos foram realizados dentro de um mesmo projeto eCognition.

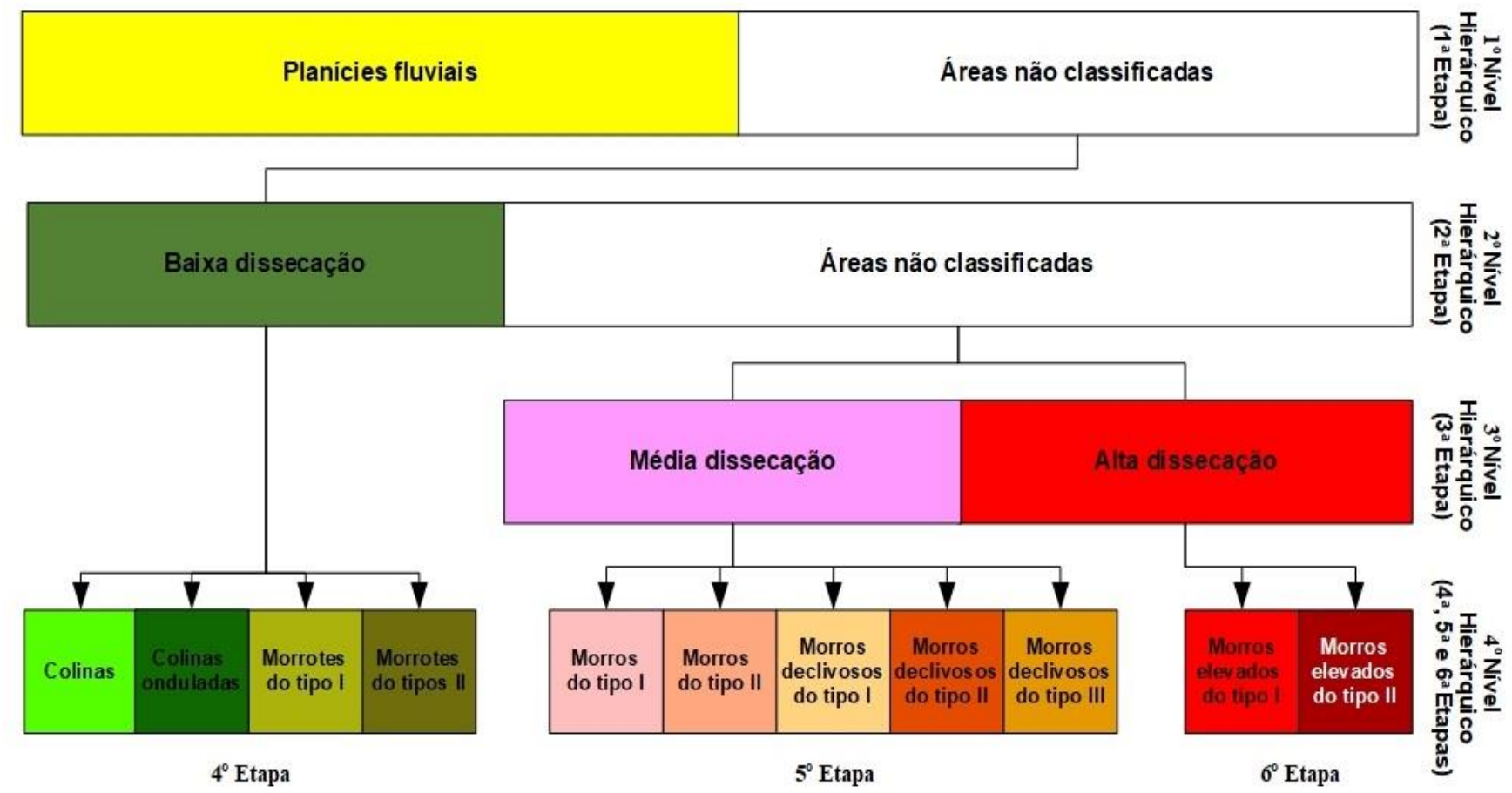

Figura 4. Fluxograma da organização hierárquica.

A Figura 5 mostra as informações acerca dos processos de segmentação e as regras de classificação para cada etapa. Nos quadros de segmentação, são indicados os parâmetros utilizados na segmentação (camadas de entrada), o raio de análise de vizinhança empregado em seu cálculo (valor em parênteses), os pesos dos critérios de semelhança e o valor do fator de escala. Nos quadros referentes à classificação, são mostradas as regras aplicadas para a classificação de cada padrão de forma de relevo, que no caso deste trabalho seguiram o modelo booleano. Os valores dos parâmetros que constam nas regras de classificação são referentes à média dos valores de todos os pixels de um determinado objeto de imagem. 

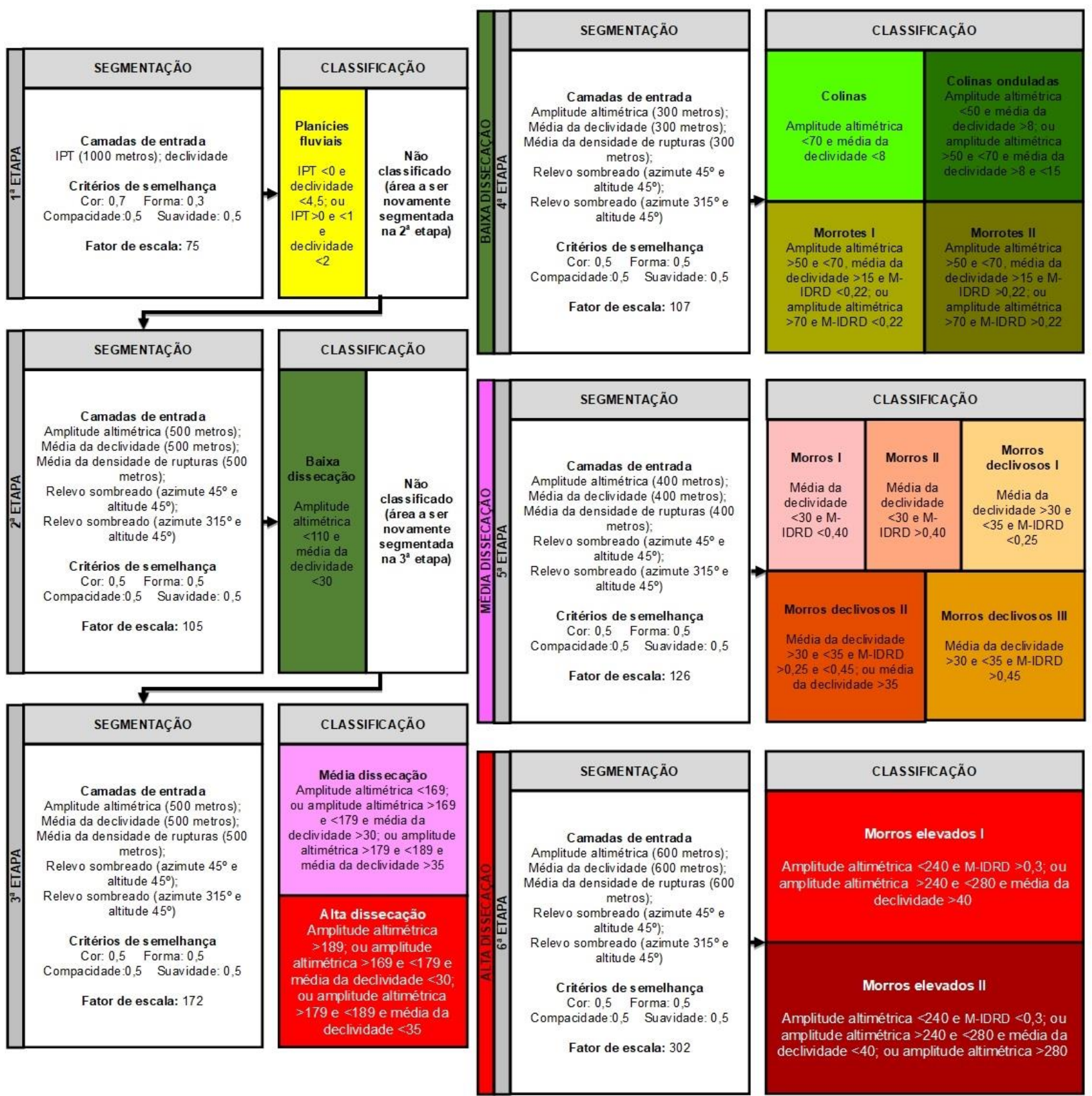

Figura 5. Fluxograma das etapas de segmentação e classificação. Os valores do IPT e da amplitude altimétrica estão em metros, enquanto os valores de declividade e média de declividade estão em porcentagem.

Em relação ao processo de segmentação, é importante frisar que os parâmetros calculados do MDE tiveram seus valores padronizados, em razão de se apresentarem com unidades de mensuração distintas. Assim, o valor mais alto foi padronizado para o valor de 255 e o valor mais baixo para 0. Entretanto, para o estabelecimento e aplicação das regras de classificação, foram utilizados os parâmetros em sua forma original.

Já em relação aos valores de escala, estes foram definidos a partir do auxílio da ferramenta Estimator of Scale Parameter (ESP), desenvolvida por Dragut, Tiede e Levick (2010) e Dragut et al. (2014). Esta ferramenta é capaz de aperfeiçoar a escolha dos valores apropriados de fator de escala. A escolha se baseia na "taxa de mudança de variância local", calculada entre valor de fator de escala e o valor seguinte. Esta taxa é apresentada em um gráfico, sendo os valores de fator de escala dos picos, que por sua vez representam o momento de estabilização na taxa de mudança da variância local, os mais apropriados para a segmentação. Deste modo, em cada uma das seis etapas de segmentação/classificação foi gerado um gráfico a partir da ferramenta ESP, e os valores de fator de escala 
apropriados foram testados, sendo escolhido que apresenta como resultado objetos de imagem mais condizentes com as formas de relevo mapeadas (Figura 6).
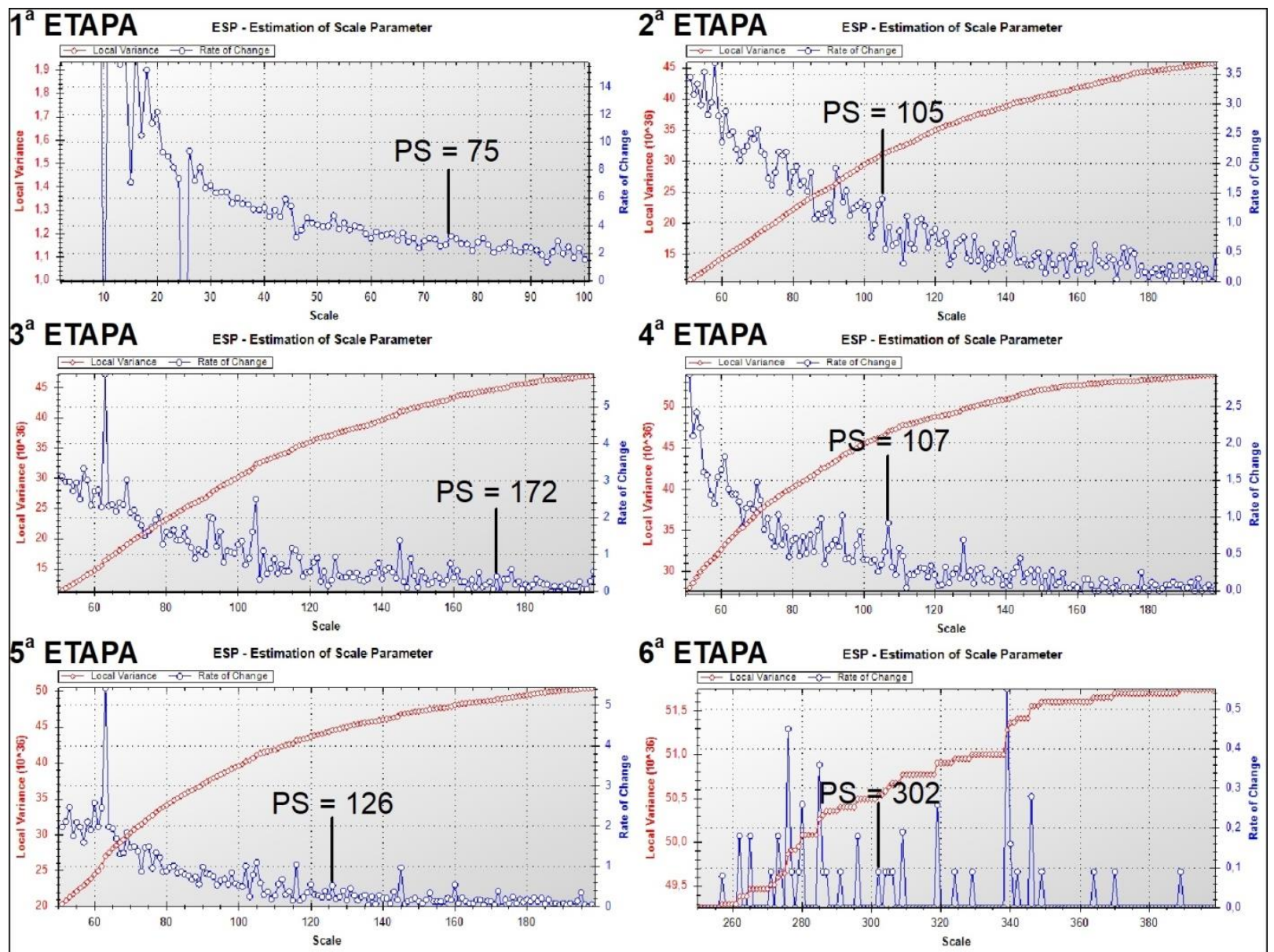

Figura 6. Gráficos da aplicação da ferramenta ESP nas seis etapas. Fonte: Os autores (2020).

\subsection{Validação da classificação}

A conferência dos resultados obtidos pelo mapeamento foi realizada por meio de duas expedições de campo, nas quais foram visitados 36 pontos (Figura 8), escolhidos previamente por estarem situados nos limites entre as classes mapeadas. Os pontos foram classificados em campo por meio de interpretação visual do relevo. Foi possível também a partir de cada ponto classificar as áreas do entorno, o que gerou um total de 155 observações de campo passíveis de comparação com os resultados da classificação semi-automatizada. A classificação por meio de interpretação visual em campo foi auxiliada por fotografias georreferenciadas tiradas em solo e a partir de voos de um drone do modelo DJI Phantom 3 Professional. Ao total, foram percorridos aproximadamente $200 \mathrm{~km}$, tanto em rodovias quanto em estradas vicinais.

Após a conferência de campo, foram identificadas inconsistências no mapeamento em relação às observações de campo. Nestes casos, os critérios de segmentação e as regras de classificação foram readequadas, visando reduzir ao máximo estas inconsistências. Na sequência, as observações de campo foram quantificadas em uma matriz de confusão, que expressa a proporção de acertos por padrão de formas de relevo e dos erros de omissão e inclusão.

\subsection{Elaboração do mapa de padrões de formas de relevo}

Após o processo de segmentação, que gerou 773 objetos de imagem, com tamanhos variando entre $44,49 \mathrm{~km}^{2}$ e $0,002 \mathrm{~km}^{2}$, foram classificados os padrões de formas de relevo. Sua representação na forma de mapa foi feita por meio de classes de relevo representadas por polígonos e diferenciadas por cores e seus matizes. 


\section{Resultados}

O processo de classificação resultou no mapeamento de 12 padrões de formas de relevo: 1) planícies fluviais, 2) colinas, 3) colinas onduladas, 4) morrotes I, 5) morrotes II, 6) morros I, 7) morros II, 8) morros declivosos I, 9) morros declivosos II, 10) morros declivosos III, 11) morros elevados I e 12) morros elevados II. A Figura 7 ilustra, por meio de fotos de campo, a morfologia predominante em cada um dos padrões de formas de relevo mapeados, a Figura 8 apresenta o mapa de padrões de formas de relevo e o Quadro 1 sintetiza as características de cada unidade:

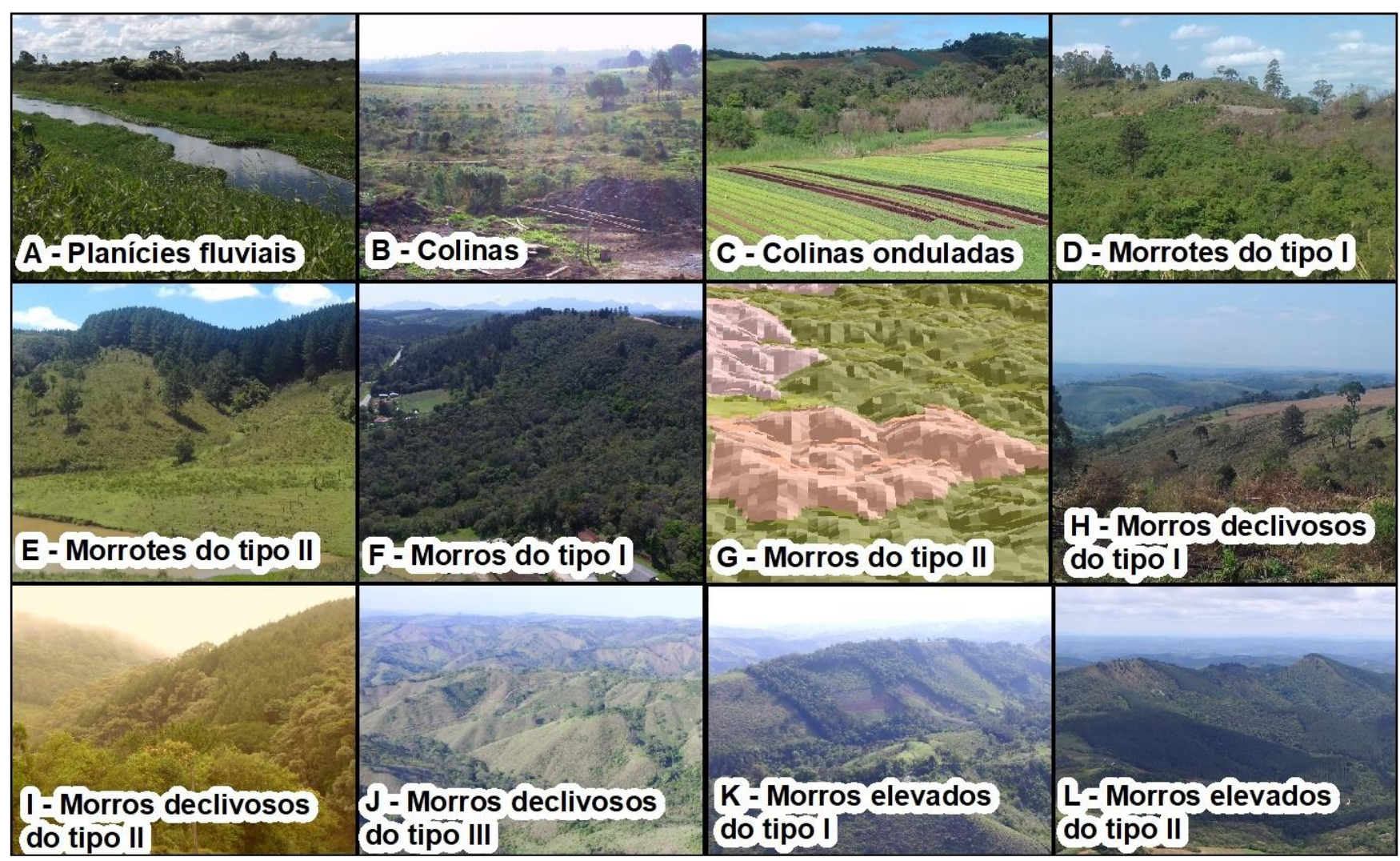

Figura 7. Fotos de campo dos padrões de formas de relevo.

Das 155 observações de campo, 119 (76,77\%) coincidiram com o mapa final. A matriz de confusão (Tabela 1) apresenta a validação em campo por padrão de forma de relevo, com a quantidade e porcentagem de acertos e a indicação do erro. Foram obtidas observações de campo para 11 das 12 classes de relevo, pois não foi possível acessar as áreas mapeadas como morros II. Além disto, os morros declivosos I tiveram apenas uma observação de campo, devido a sua pouca representatividade espacial na área de estudo. Dos padrões de formas de relevo, as planícies fluviais, colinas, morros declivosos III, morros declivosos I e morros I apresentaram percentual de acerto acima de $95 \%$. Os percentuais mais baixos foram dos morros declivosos II, morrotes II, colinas onduladas, morrotes I e morros elevados I, todos abaixo ou igual a $75 \%$. 


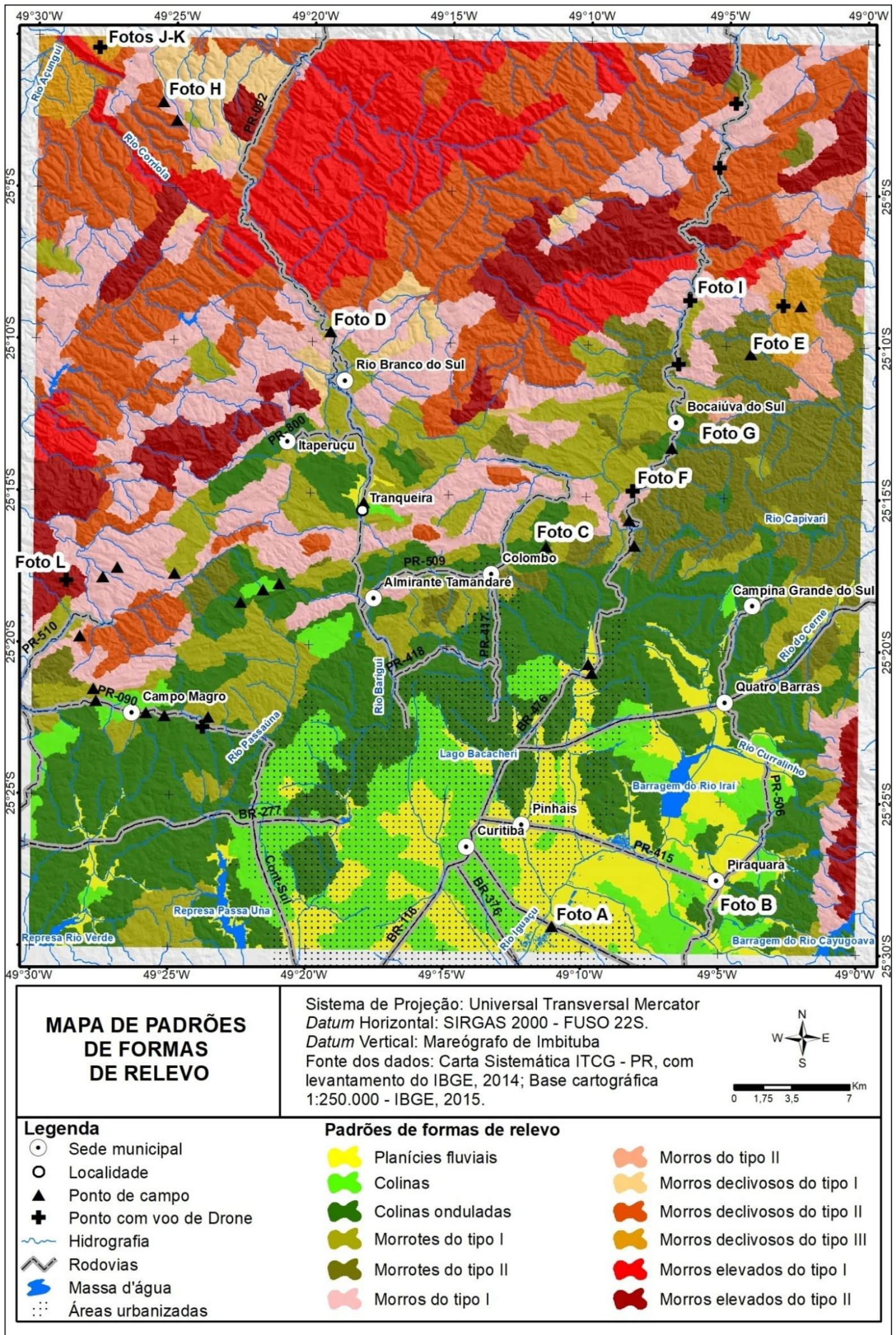

Figura 8. Mapa de padrões de formas de relevo. 
Quadro 1. Caracterização dos padrões de formas de relevo.

\begin{tabular}{|c|c|c|c|c|}
\hline $\begin{array}{l}\text { Padrão de formas de } \\
\text { relevo }\end{array}$ & Area $\left(\mathbf{k m}^{2}\right)$ & $\begin{array}{l}\text { Amplitude } \\
\text { altimétrica }\end{array}$ & Declividade & Descrição generalizada dos padrões de formas de relevo \\
\hline $\begin{array}{l}\text { Planícies fluviais } \\
\text { (Figura 7A) }\end{array}$ & $\begin{array}{c}213,4 \\
(7,64 \%)\end{array}$ & & $\begin{array}{c}\text { Varia entre } 0,5 \text { e } \\
5,3 \% \text {; com média } \\
\text { de } 2,25 \%\end{array}$ & Áreas planas localizadas nos fundos dos vales. \\
\hline Colinas (Figura 7B) & $\begin{array}{c}213,6 \\
(7,66 \%)\end{array}$ & $\begin{array}{l}\text { Varia entre } 36,4 \text { e } \\
12 \mathrm{~m} \text {, com média } \\
\text { de } 24,8 \mathrm{~m} .\end{array}$ & $\begin{array}{c}\text { Varia entre } 7,9 \text { e } \\
2,1 \% \text {, com média } \\
\text { de } 5,2 \%\end{array}$ & $\begin{array}{l}\text { Vertentes retilíneas com comprimento variando entre } 500 \text { e } 1000 \mathrm{~m} \text {, } \\
\text { predomínio de topos alongados (SALAMUNI; EBERT; HASUI, } \\
\text { 2004; SALAMUNI et al., 2013) e em menor área topos } \\
\text { arredondados. }\end{array}$ \\
\hline $\begin{array}{l}\text { Colinas onduladas } \\
\text { (Figura 7C) }\end{array}$ & $\begin{array}{c}559,28 \\
(20,05 \%)\end{array}$ & $\begin{array}{c}\text { Varia entre } 68 \text { e } \\
31,2 \mathrm{~m}, \text { com média } \\
\text { de } 44,4 \mathrm{~m} .\end{array} \mid$ & $\begin{array}{c}\text { Varia entre } 15,1 \text { e } \\
7,4 \% \text {, com média } \\
\text { de } 11,2 \%\end{array}$ & $\begin{array}{l}\text { Vertentes côncavas com comprimento variando entre } 250 \text { e } 400 \mathrm{~m} \text { e } \\
\text { topos planos (SALAMUNI; EBERT; HASUI, 2004; SALAMUNI et } \\
\text { al., 2013) ou topos alongados nas direções NW-SE e NE-SW. }\end{array}$ \\
\hline $\begin{array}{l}\text { Morrotes do tipo I } \\
\quad \text { (Figura 7D) }\end{array}$ & $\begin{array}{c}284,32 \\
(10,19 \%)\end{array}$ & $\begin{array}{c}\text { Varia entre } 90,2 \text { e } \\
51,5 \mathrm{~m}, \text { com média } \\
\text { de } 67,2 \mathrm{~m} .\end{array} \mid$ & $\begin{array}{l}\text { Varia entre } 24,3 \text { e } \\
15 \% \text {, com média } \\
\text { de } 18,2 \%\end{array}$ & $\begin{array}{l}\text { Predomínio de topos alongados em cristas de direções NE-SW ou } \\
\text { NW-SE e vertentes alongadas e suaves e fundos de vale rebaixados. }\end{array}$ \\
\hline $\begin{array}{l}\text { Morrotes do tipo II } \\
\quad \text { (Figura 7E) }\end{array}$ & $\begin{array}{l}206,33 \\
(7,40 \%)\end{array}$ & $\begin{array}{c}\text { Varia entre } 96,5 \text { e } \\
56,7 \mathrm{~m}, \text { com média } \\
\text { de } 73,1 \mathrm{~m} .\end{array} \mid$ & $\begin{array}{c}\text { Varia entre } 30,8 \text { e } \\
17,6 \% \text {, com média } \\
\text { de } 23,2 \%\end{array}$ & $\begin{array}{l}\text { Predomínio de topos arredondados, vertentes convexas e com } \\
\text { comprimentos entre } 150 \text { e } 350 \mathrm{~m} \text {, e vales entalhados com alta } \\
\text { densidade de rupturas no relevo devido à alta densidade de } \\
\text { drenagens. }\end{array}$ \\
\hline $\begin{array}{l}\text { Morros do tipo I } \\
\quad \text { (Figura 7F) }\end{array}$ & $\begin{array}{c}378,84 \\
(13,58 \%)\end{array}$ & $\begin{array}{c}\text { Varia entre } 159 \text { e } \\
90,9 \mathrm{~m} \text {, com média } \\
\text { de } 116 \mathrm{~m} .\end{array}$ & $\begin{array}{c}\text { Varia entre } 29,7 \text { e } \\
18,6 \% \text {, com média } \\
\text { de } 25,6 \%\end{array}$ & $\begin{array}{l}\text { Vertentes com comprimento variando entre } 200 \text { e } 500 \mathrm{~m} \text {, topos } \\
\text { alongados em cristas com direção NE-SW ou topos arredondados. }\end{array}$ \\
\hline $\begin{array}{l}\text { Morros do tipo II } \\
\quad \text { (Figura 7G) }\end{array}$ & $\begin{array}{c}28,88 \\
(1,04 \%)\end{array}$ & $\begin{array}{c}\text { Varia entre } 123,5 \text { e } \\
101 \mathrm{~m} \text {, com média } \\
\text { de } 109,8 \mathrm{~m} .\end{array}$ & $\begin{array}{c}\text { Varia entre } 29,3 \text { e } \\
27,7 \% \text {, com média } \\
\text { de } 28,8 \%\end{array}$ & $\begin{array}{c}\text { Topos arredondados e vertentes convexas com comprimentos entre } \\
200 \mathrm{~m} \text { e } 300 \mathrm{~m} \text { e se diferenciam dos morros I devido à alta densidade } \\
\text { de rupturas de declividade. }\end{array}$ \\
\hline $\begin{array}{l}\text { Morros declivosos do } \\
\text { tipo I (Figura 7H) }\end{array}$ & $\begin{array}{c}49,68 \\
(1,78 \%)\end{array}$ & $\begin{array}{c}\text { Varia entre } 181,1 \mathrm{e} \\
104,5 \mathrm{~m}, \mathrm{com} \\
\text { média de } 139,2 \mathrm{~m}\end{array}$ & $\begin{array}{c}\text { Varia entre } 33,4 \text { e } \\
30 \% \text {, com média } \\
\text { de } 31,4 \%\end{array}$ & $\begin{array}{l}\text { Topos alongados com orientações nas direções N-S, NW-SE e NE- } \\
\text { SW, e vertentes com comprimento entre } 200 \text { e } 400 \mathrm{~m} \text {. }\end{array}$ \\
\hline $\begin{array}{l}\text { Morros declivosos do } \\
\text { tipo II (Figura 7I) }\end{array}$ & $\begin{array}{c}421,15 \\
(15,10 \%)\end{array}$ & $\begin{array}{c}\text { Varia entre } 201,6 \mathrm{e} \\
112,8 \mathrm{~m}, \mathrm{com} \\
\text { média de } 149,8 \mathrm{~m}\end{array}$ & $\begin{array}{c}\text { Varia entre } 43,3 \text { e } \\
29,1 \% \text {, com média } \\
\text { de } 35,2 \%\end{array}$ & $\begin{array}{c}\text { Os topos são alongados em cristas na direção NE-SW ou os topos } \\
\text { são arredondados; as vertentes possuem comprimentos que variam } \\
\text { entre } 200 \text { e } 500 \mathrm{~m} \text { e os vales muito entalhados. }\end{array}$ \\
\hline $\begin{array}{l}\text { Morros declivosos do } \\
\text { tipo III (Figura 7J) }\end{array}$ & $\begin{array}{c}33,45 \\
(1,20 \%)\end{array}$ & $\begin{array}{c}\text { Varia entre } 132,2 \mathrm{e} \\
117,8 \mathrm{~m}, \mathrm{com} \\
\text { média de } 123 \mathrm{~m} .\end{array}$ & $\begin{array}{c}\text { Varia entre } 34,3 \text { e } \\
31,1 \% \text {, com média } \\
\text { de } 32,6 \%\end{array}$ & $\begin{array}{c}\text { Topos são arredondados ou alongados na direção NW-SE, as } \\
\text { vertentes possuem comprimentos variando entre } 100 \text { e } 400 \mathrm{~m} \text { e se } \\
\text { diferenciam em relação aos demais morros declivosos devido a alta } \\
\text { densidade de rupturas no relevo. }\end{array}$ \\
\hline $\begin{array}{l}\text { Morros elevados do } \\
\text { tipo I (Figura 7K) }\end{array}$ & $\begin{array}{c}239,56 \\
(8,59 \%)\end{array}$ & $\begin{array}{c}\text { Varia entre } 263,9 \text { e } \\
199,6 \mathrm{~m}, \text { com } \\
\text { média de } 236,2 \mathrm{~m} \text {. }\end{array}$ & $\begin{array}{c}\text { Varia entre } 45 \text { e } \\
33,6 \% \text {, com média } \\
\text { de } 40,8 \%\end{array}$ & $\begin{array}{c}\text { Topos alongados e em cristas na direção NW-SE, vertentes em geral } \\
\text { entre } 200 \text { e } 600 \mathrm{~m} \text {, (entretanto em algumas porções podem atingir } \\
\text { até } 850 \mathrm{~m} \text { ) e vales em "V" muito entalhados. }\end{array}$ \\
\hline $\begin{array}{l}\text { Morros elevados do } \\
\text { tipo II (Figura 7L) }\end{array}$ & $\begin{array}{l}161,64 \\
(5,79 \%)\end{array}$ & $\begin{array}{c}\text { Varia entre } 336,6 \mathrm{e} \\
208,3 \mathrm{~m}, \mathrm{com} \\
\text { média de } 249,8 \mathrm{~m}\end{array}$ & $\begin{array}{c}\text { Varia entre } 43 \text { e } \\
31,1 \% \text {, com média } \\
\text { de } 36,6 \%\end{array}$ & $\begin{array}{l}\text { Topos alongados e em cristas nas direções NW-SE e NE-SW, e } \\
\text { vertentes longas, entre } 500 \text { e } 1.000 \mathrm{~m} \text { de comprimento. }\end{array}$ \\
\hline
\end{tabular}

O processo de segmentação, fruto das seis etapas, resultou em 773 objetos de imagem que representam uma forma de relevo individualizada ou um grupo de formas de relevo individualizadas com características semelhantes. Estes objetos apresentaram áreas que variaram entre $44,49 \mathrm{~km}^{2}$ e $0,002 \mathrm{~km}^{2}$. Levando em consideração a adaptação da hierarquia taxonômica de unidades de relevo do Dikau (1989) por Bortolini, Silveira e Silveira (2017) e Bortolini et al. (2018), que definiu $1 \mathrm{~km}^{2}$ como área mínima mapeável para padrões de formas de relevo, 87 objetos de imagem não se enquadram neste critério. Porém, destes, 77 são objetos que são adjacentes a outros objetos de imagem de mesma classe de relevo ou se localizam no limite da área de estudo, tendo assim uma continuidade fora do recorte do estudo que lhe daria uma área superior a $1 \mathrm{~km}^{2}$. 
Tabela 1. Observações de validação de campo.

\begin{tabular}{|c|c|c|c|c|c|c|c|c|c|c|c|c|c|}
\hline Padrão $^{1}$ & PLF & COL & $\mathrm{CON}$ & MT1 & MT2 & MO1 & MO2 & MD1 & MD2 & MD3 & ME1 & ME2 & Total \\
\hline PLF & $3(100 \%)$ & & & & & & & & & & & & 3 \\
\hline COL & & $7(100 \%)$ & & & & & & & & & & & 7 \\
\hline $\mathrm{CON}$ & 1 & 1 & $12(71 \%)$ & & & 2 & & & & & & & 17 \\
\hline MT1 & & 1 & 5 & $25(74 \%)$ & 1 & 2 & & & & & & & 34 \\
\hline MT2 & & & & 4 & $11(50 \%)$ & 7 & & & & & & & 22 \\
\hline MO1 & & & & 1 & & $23(92 \%)$ & & & & & & & 25 \\
\hline MO2 & & & & & & & 0 & & & & & & 0 \\
\hline MD1 & & & & & & & & $1(100 \%)$ & & & & & 1 \\
\hline MD2 & & & & & & 6 & & & $9(60 \%)$ & & & & 15 \\
\hline MD3 & & & & & & & & & & $17(100 \%$ & & & 17 \\
\hline ME1 & & & & & & & & & 1 & & $3(75 \%)$ & & 4 \\
\hline ME2 & & & & & & & & & 2 & & & $8(80 \%)$ & 10 \\
\hline Total & 4 & 9 & 17 & 31 & 12 & 40 & 0 & 1 & 13 & 17 & 3 & 8 & 155 \\
\hline
\end{tabular}

${ }^{1}$ planícies fluviais (PLF); colinas (COL); colinas onduladas (CON); morrotes do tipo I (MT1); morrotes do tipo II (MT2); morros do tipo I (MO1); morros do tipo II (MO2); morros declivosos do tipo I (MD1); morros declivosos do tipo II (MD2); morros declivosos do tipo III (MD3); morros elevados do tipo I (ME1); e morros elevados do tipo II (ME2). Obs: as informações das linhas se referem as observações de campo e as informações das colunas se referem as informações do mapeamento semi-automatizado.

\section{Discussões}

Como evidenciam os resultados, a metodologia empregada apresentou na classificação acerto superior a três quartos dos pontos validados em campo. Além disto, apenas 10 objetos de imagem segmentados não se enquadram no critério de área mínima mapeável, o que representa menos de $0,3 \%$ da área de estudo. Isto evidencia que o método apresenta potencial para a realização de mapeamento condizente com a realidade observada na validação de campo e para mapeamento de formas de relevo com tamanhos adequados a escala geomorfológica pretendida, sem a necessidade de aplicação de filtros de generalização posterior a classificação, pois o próprio procedimento de segmentação já realiza a generalização necessária, sendo esta controlada pelo fator de escala.

Como citado nos resultados, cada objeto de imagem deve representar uma forma de relevo individual, ou um grupo de formas de relevo semelhantes. Sendo assim, o limite teórico entre duas formas de relevo (com exceção das planícies fluviais), e consequentemente dos objetos de imagem, se daria nas descontinuidades do relevo marcadas pela convergência de fluxo hídrico, como as drenagens de fundo de vales (Figura 9A e 9B). Este objetivo foi alcançado, principalmente devido à utilização dos relevos sombreados, pois foi o único parâmetro utilizado no processo de segmentação a partir da segunda etapa que foi calculado com uso de janela móvel 3x3 pixels. Estes preservaram de maneira mais fidedigna as descontinuidades do relevo presentes nas áreas de fundo de vale e nos divisores de água, fazendo com que os limites entre os objetos de imagem fossem condizentes em relação ao limite teórico entre formas de relevo. Entretanto, é preciso levar em consideração que foram utilizados para este processo de segmentação relevos sombreados de somente dois azimutes $\left(45^{\circ}\right.$ e $\left.315^{\circ}\right)$, visando privilegiar apenas as principais 
orientações das estruturas geológicas refletidas do relevo na área de estudo. A utilização de outras direções de azimute poderia apresentar resultados diferentes, dando mais ênfase assim na segmentação de feições de relevo com as demais orientações, porém o que se notou é que as duas direções empregadas foram eficientes no experimento realizado. A replicação do método em outras regiões requer a análise prévia das orientações que prevalecem no relevo local.

Apenas alguns objetos de imagem não corresponderam ao esperado, apresentando limites no meio da vertente (Figura 9C) ou limites nos divisores de água no (Figura 9D). No primeiro caso, o denominado de efeito de transição, ocorreu quando as vertentes de uma área são mais longas ou curtas do que o comprimento do raio empregado no cálculo dos parâmetros. Contudo, este erro ocorreu apenas em áreas que correspondem a 0,5\% da área de estudo. Já o segundo caso (que correspondeu a 0,8\% da área de estudo), ocorreu em formas de relevo que possuem vertentes com alguma característica morfométrica muito heterogênea em relação às demais vertentes que a compõe, ou em formas de relevo que possuem vertentes que no cálculo do relevo sombreado receberam iluminações muito distintas devido a sua orientação. Porém, muitos destes objetos acabaram por vezes classificados como um mesmo padrão, não acarretando em erros na classificação.

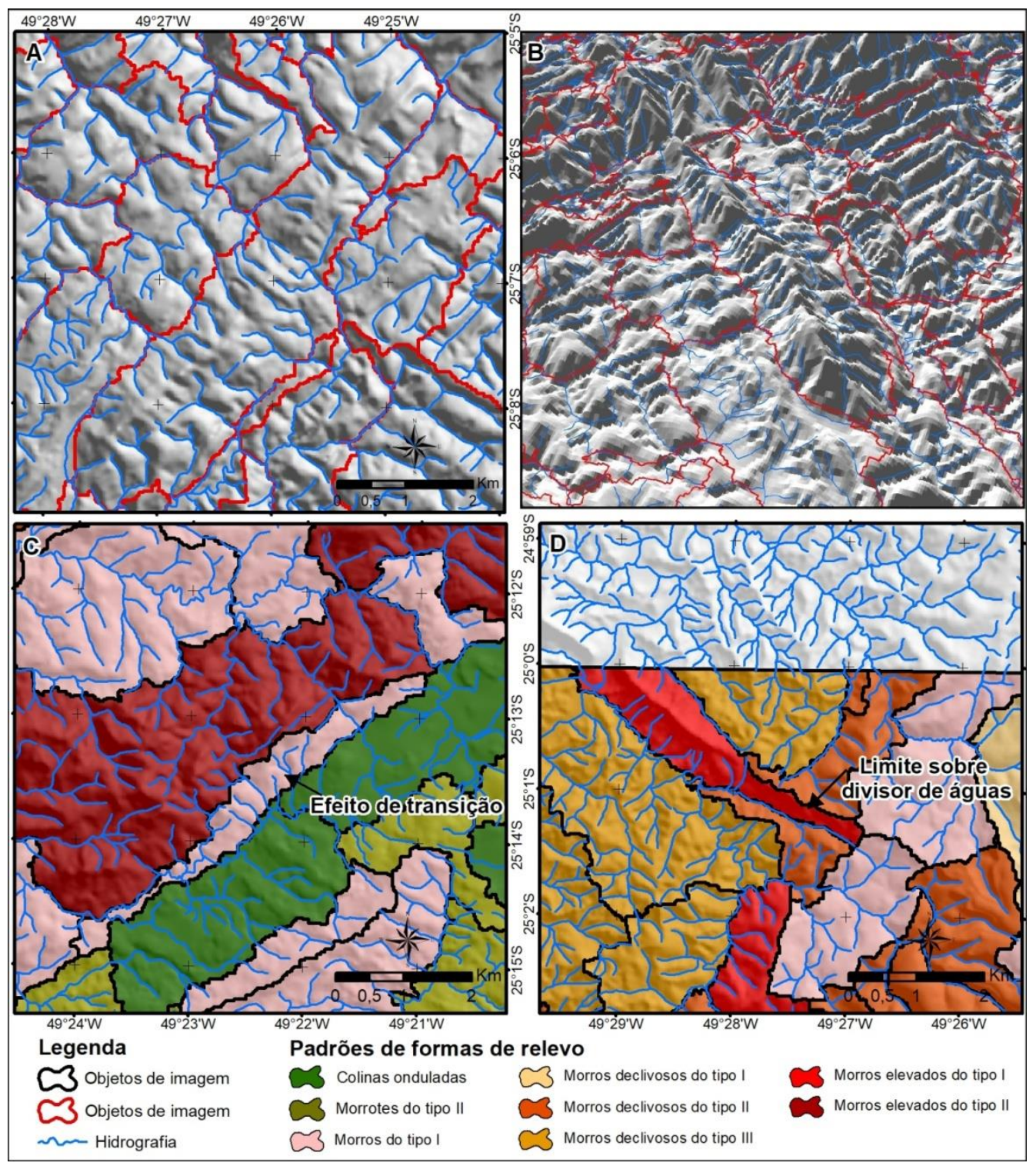

Figura 9. Visão vertical (A) e 3D (B) de um objeto de imagem corretamente segmentado; limite com "efeito de transição" (C); e limite dos objetos de imagem no divisor de águas (D). 
Além das questões referentes ao traçado dos limites entre os objetos de imagem, algumas áreas apresentaram inconsistências relacionadas à generalização insuficiente e à generalização excessiva no processo de segmentação, que somam 1,3\% da área de estudo. Quatro exemplos são mostrados nas Figuras 10A, 10B e 10C. Na Figura 10A é ilustrado o caso de generalização insuficiente, onde a área de uma planície fluvial e o seu entorno, foram segmentados em um objeto de imagem que foi classificado como colinas onduladas. Porém, esta planície tem sua área inferior a $1 \mathrm{~km}^{2}$, e seu entorno é composto pelas vertentes dos morrotes, sendo assim, este objeto não representa uma forma de relevo individualizada e por isso deveria ser agregado a algum objeto vizinho.
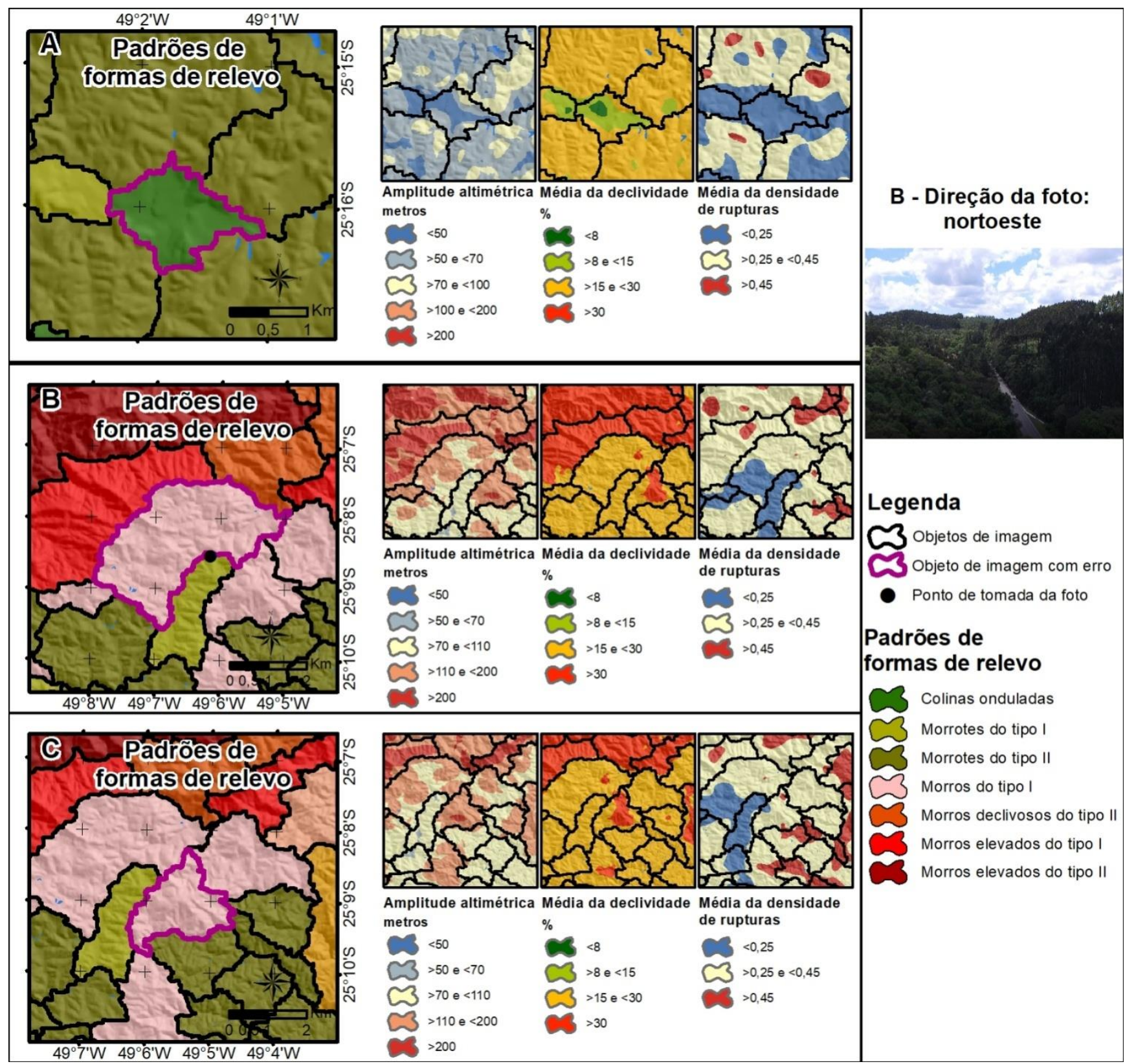

Figura 10. Exemplos de objetos de imagem que apresentaram generalização insuficiente (A) ou excessiva (B e C).

Na Figura 10B é ilustrado o caso de generalização excessiva, onde duas áreas de morrotes II foram generalizadas em um objeto de imagem classificado como morros I. Este tipo de erro resulta do fato de que apenas um dos parâmetros apresentou valores heterogêneos, sendo estes suficientes para caracterizar diferentes padrões de formas de relevo. Contudo, os demais têm valores homogêneos, fazendo com que o algoritmo segmente toda a área em um único objeto de imagem. Além da delimitação inconsistente dos objetos de imagem, a generalização Revista Brasileira de Geomorfologia. 2021, v. 22, n. 4; (Out-Dez) DOI: 10.20502/rbg.v22i4.1987 http://www.lsie.unb.br/rbg/ 
excessiva pode acarretar em erros na posterior classificação destes, pois interfere no valor médio dos parâmetros. Isto é ilustrado na Figura 10C, onde uma área de morros declivosos II foi classificada como morros I, devido ao fato do objeto de imagem que representa essa forma de relevo englobar áreas de seu entorno que apresentam declividade mais baixa, fazendo com que o valor médio deste parâmetro fosse diminuído. Assim, o objeto foi classificado como uma classe de relevo diferente da classe observada em campo.

Um erro por generalização excessiva foi também encontrado em áreas classificadas como planície fluvial, que se caracterizam como um padrão de forma de relevo que em muitos casos apresenta seus limites em áreas com sutis descontinuidades no relevo. Estes erros correspondem a 1,8\% da área de estudo. A necessidade do uso de um fator de escala com valor que evite a segmentação de objetos de imagem menores que a área mínima mapeável fez o algoritmo segmentar objetos com excessiva heterogeneidade interna, acarretando no erro observado na Figura 11. Nesse mesmo sentido, pode-se afirmar que o ajuste do fator de escala é um fator relevante na redução de erros desta natureza, pois é o critério que controla a homogeneidade/heterogeneidade dos objetos de imagem, e consequentemente seu respectivo tamanho. Entretanto, mesmo quando aplicado o valor de fator de escala mais ajustado para segmentar os objetos de imagem referentes a um relevo com mesmo nível de dissecação, alguns destes objetos apresentam erros devido à grande variedade de comprimentos de vertentes das formas de relevo. Outro fator que influenciou este cenário foram os pesos dos critérios de semelhança. Para a etapa foi utilizado peso 0,7 para o critério cor, por este ser mais sensível a heterogeneidade dos valores dos parâmetros.

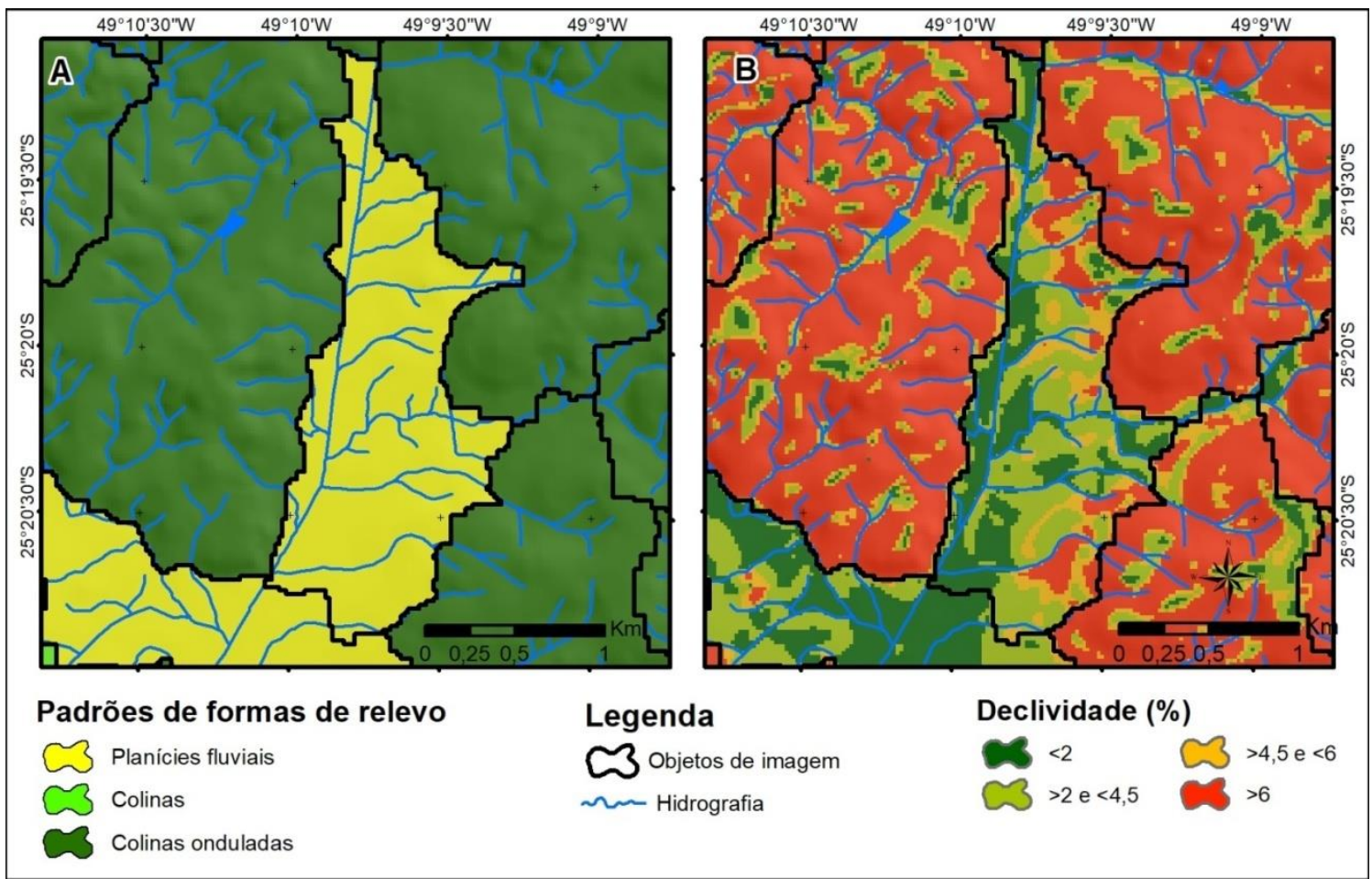

Figura 11. Generalização excessiva em área de planície fluvial.

Além dos erros associados à segmentação, foi observado um erro relacionado à classificação dos objetos de imagem que totaliza $0,7 \%$ da área de estudo. Este erro ocorreu em objetos classificados como morrotes I e morrotes II, que são diferenciados pela média da densidade de relevo. O limiar entre estes dois relevos é o valor 0,22, entretanto há objetos de imagem que possuem valor de média de densidade de ruptura entre 0,19 e 0,22 que são classificados como morrotes I, mas possuem características de morrotes II (Figura 12A), como por exemplos os topos arredondados. O contrário também ocorreu (Figura 12B), com áreas classificadas como morrotes II e que possuem características dos morrotes I. O último caso é se trata de morrotes alongados de maior amplitude Revista Brasileira de Geomorfologia. 2021, v. 22, n. 4; (Out-Dez) DOI: 10.20502/rbg.v22i4.1987 http://www.lsie.unb.br/rbg/ 
altimétrica do que os morrotes similares, e com terço médio inferior das vertentes mais declivoso, apresentando assim uma média da densidade de rupturas dos objetos mais alta, resultando na classificação como morrotes II.

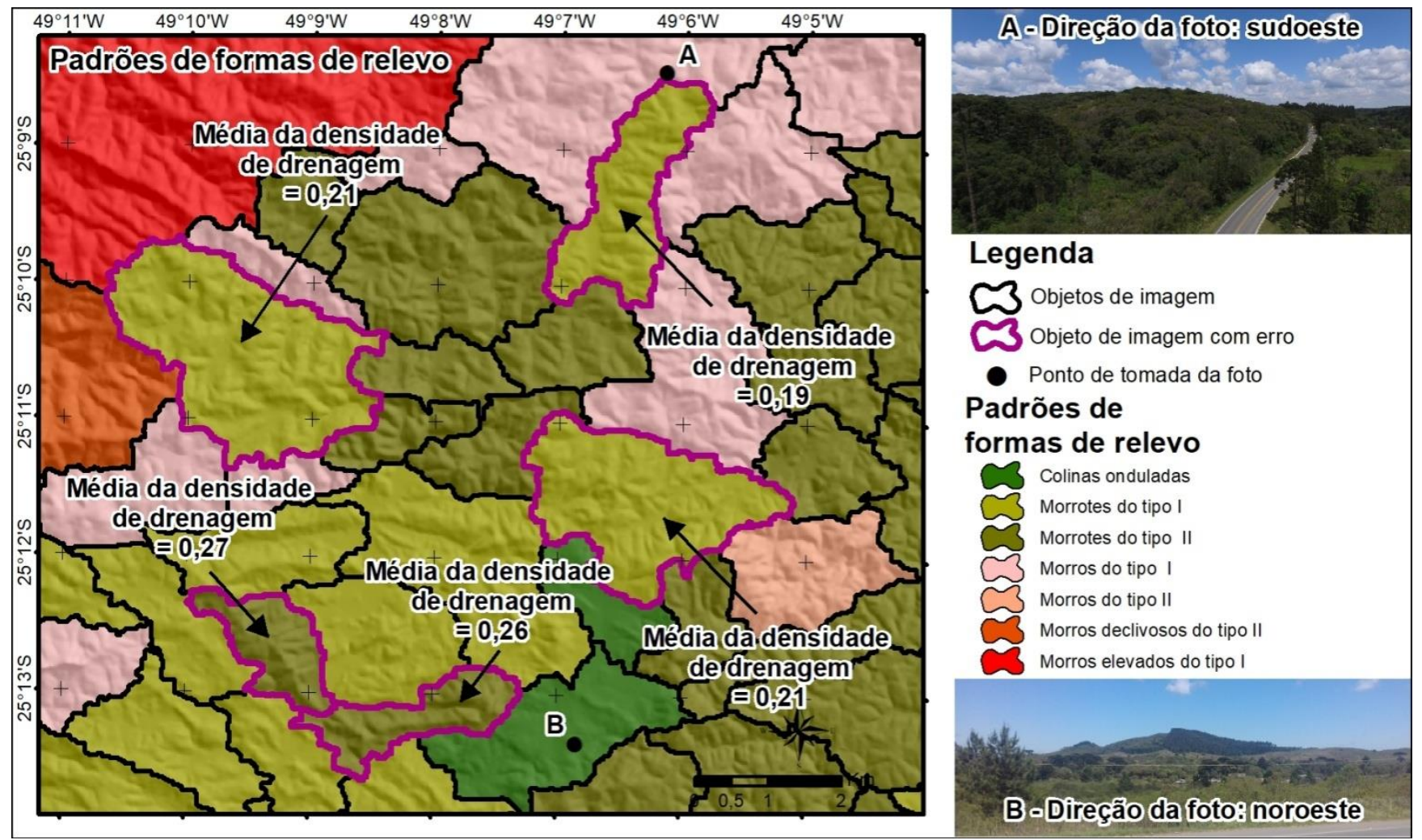

Figura 12. Erro de classificação nos morrotes do tipo I e morrotes do tipo II.

Um dos grandes desafios encontrados na formulação desta proposta metodológica foi viabilizá-la para mapear toda uma área que engloba relevos de diferentes características geomorfológicas. Para isso, a segmentação e classificação, realizadas nas três primeiras etapas, contribuíram para reduzir a heterogeneidade das áreas a serem segmentadas e classificadas por padrões de formas de relevo nas três últimas etapas. Deste modo, foi possível aplicar critérios de segmentação e regras de classificação, adequados para áreas menores e geomorfologicamente mais semelhantes, caracterizadas pelo mesmo nível de dissecação, tornando os erros de segmentação exceções neste método. Além disto, permitiu que os critérios para a segmentação e classificação de um determinado padrão de forma de relevo fossem uniformes para toda a área de estudo, independente da sua complexidade em relação a características genéticas ou morfográficas, reduzindo assim a subjetividade do processo. Ou seja, é possível mapear um padrão de formas de relevo que se desenvolveu sobre diferentes contextos geológicos e geomorfológicos utilizando os mesmos critérios e parâmetros. Este fato foi de grande valor nesta aplicação, tendo em vista que a área mapeada se caracteriza pela alta diversidade geológica e geomorfológica, além de evidenciar a viabilidade da replicabilidade do método para outras áreas de estudo.

O método empregado possibilitou, com sucesso, a automatização e redução de erros no traçado dos limites entre padrões de formas de relevo, além de apresentar acerto de $77 \%$ na classificação final. No entanto, o estabelecimento dos critérios de segmentação e das regras de classificação é dotado de decisões subjetivas, dadas a partir da experiência do mapeador. No que tange especificamente ao processo de segmentação, o estabelecimento dos critérios de semelhança foram definidos por testes de tentativa e erro, enquanto o estabelecimento do fator de escala foi auxiliado pela ferramenta ESP, mas a escolha dos valores finais foi decisão do usuário. Assim, é recomendado o profundo conhecimento das características geológicas e geomorfológicas da área a ser mapeada 
por parte do mapeador, com a imprescindível necessidade da realização de campanhas de campo anteriores e posteriores ao mapeamento.

Por fim, é preciso ressaltar que esta é uma proposta metodológica, cujo propósito foi a aplicabilidade do algoritmo segmentação multiresolucional no mapeamento digital de relevo. A resposta positiva obtida nesta área de estudo, por meio do mapeamento padrões de formas de relevo, demonstrou que o algoritmo tem potencialidade de aplicação para o mapeando do relevo em outras áreas e/ou escalas geomorfológicas, para tanto, diferentes critérios de segmentação e diferentes regras de classificação, com uso de diferentes parâmetros, deverão ser avaliados e empregados.

\section{Conclusões}

O emprego do algoritmo de segmentação multiresolucional demonstrou potencialidade no mapeamento de padrões de formas de relevo, demonstrado pelos resultados fidedignos com a realidade observada em campo e consonantes com a escala geomorfológica pretendida.

O trabalho evidenciou potencialidades, como a otimização do processo de mapeamento e a redução da subjetividade na delimitação entre as classes de padrões formas de relevo detectadas, bem como a adequação a escala geomorfológica pretendida e a replicabilidade.

Apesar da redução da subjetividade na delimitação das formas de relevo, os critérios de segmentação e as regras de classificação demandam de experiência no processo de operação por parte do mapeador, inserindo assim subjetividade no método. As definições dos pesos dos critérios de semelhança e do fator de escala são fruto de testes e avaliação visual do mapeador, abrindo espaço assim para novas pesquisas que reduzam estas subjetividades. Por outro lado, o algoritmo oferece uma série de funcionalidades que não foram exploradas neste trabalho e que podem contribuir no mapeamento semiautomatizado de padrões de formas de relevo, como por exemplo, a classificação por lógica fuzzy, o uso de relações topológicas entre os objetos de imagem para a classificação e o uso de informações sobre a textura dos objetos de imagem.

As limitações do método, sobretudos associados ao processo de segmentação dos objetos de imagem, indicam a demanda por mais pesquisas sobre este algoritmo para fins de classificação do relevo. Portanto, recomenda-se seu emprego em trabalhos de classificação digital de formas de relevo em outras escalas, ou em outras áreas de estudo, mediante adaptações, em especial na escolha dos parâmetros, pois esses devem expressar o arranjo morfológico do relevo.

Contribuições dos Autores: $\mathrm{O}$ artigo é fruto da pesquisa desenvolvida por meio da dissertação de mestrado do primeiro autor, Willian Bortolini, sob a orientação do segundo autor, Claudinei Taborda da Silveira. A concepção do trabalho está alicerçada na linha de pesquisa do orientador e contou com financiamento de projeto sob sua coordenação para as atividades de campo. A metodologia e a operação dos softwares foram executadas pelo primeiro autor, a validação, preparação e análise dos dados, foram realizadas em conjunto por ambos; a escrita do artigo foi redigida pelo primeiro autor, porém contou com inúmeras fases de revisão e aprimoramento do segundo autor. Os autores leram e concordaram com a versão publicada do manuscrito.

Financiamento: a pesquisa contou com bolsa de fomento de nível mestrado, concedida pela Coordenação de Aperfeiçoamento de Pessoal de Nível Superior (CAPES) por meio do Programa de Pós-Graduação em Geografia da Universidade Federal do Paraná (PPGGEO-UFPR). Contou com recurso financeiros do Conselho Nacional de Desenvolvimento Científico e Tecnológico (CNPq),que contribuíram com a realização do trabalho e os levantamentos de campo, por meio do projeto "Desenvolvimento metodológico e aplicações modelagem digital do terreno no mapeamento geomorfológico", Processo no 434343/2018-8, Apoio a Projetos de Pesquisa / MCTI/CNPQ/Universal 28/2018 - Faixa B.

Agradecimentos: Ao Laboratório de Sensoriamento Remoto e ao Programa de Pós-Graduação em Ciências Geodésicas (Departamento de Geomática - UFPR) por cederem o uso do software eCognition; e a equipe do LAGEO-UFPR (Laboratório de Pesquisas em Geomorfologia e Geotecnologias); 
Conflito de Interesse: Os autores declaram não haver conflito de interesse. Os financiadores não tiveram interferência no desenvolvimento do estudo; na coleta, análise ou interpretação dos dados; na redação do manuscrito, ou na decisão de publicar os resultados".

\section{Referências}

1. ANDERS, N. S.; SEIJMONSBERGEN, A. C.; BOUTEN, W. Segmentation optimization and stratified object-based analysis for semi-automated geomorphological mapping.Remote Sensing of Environment. v. 115, p. 2976-2985, 2011. DOI: 10.1016/j.rse.2011.05.007

2. ANDERS, N. S.; SEIJMONSBERGEN, A. C.; BOUTEN, W. Geomorphological change detection using object-based feature from multi-temporal LiDAR data. Geoscienceand Remote Letters. v. 10. n. 6. p. 1585-1591. 2013. DOI: 10.1109/LGRS.2013.2262317

3. ANTONIO, M. M. Z. Uma metodologia para análise de imagens usando segmentações específicas por classe. 2013.169 p. Tese (Doutorado em Engenharia Elétrica). Departamento de Engenharia Elétrica, Pontifícia Universidade Católica do Rio de Janeiro, Rio de Janeiro.

4. ANTUNES, A. F. B. Classificação de ambiente ciliar baseada em orientação a objeto de imagens de alta resolução espacial. 2003. 147p. Tese (Doutorado em Ciências Geodésicas). Curso de Pós-Graduação em Ciências Geodésicas, Universidade Federal do Paraná, Curitiba, Paraná.

5. ASSELEN, S.; SEIJMONSBERGEN, A. C. Expert-driven semi-automated geomorfphological mapping for a mountains area using a laser DTM. Geomorphology. v. 78. p. 309-310. 2006. DOI: 10.1016/j.geomorph.2006.01.037

6. BAATZ, M.; SCHAPE, A. Multiresolution segmentation: an optimization approach for high quality multi-scale image segmentation. In: Strobl, J., Blaschke, T.,Griesebner, G. (Eds.), Angewandte Geographische Informations- Verarbeitung, vol. XII. Wichmann, Heidelberg, pp. 12-23. 2000.

7. BENZ, U. C.; HOFMANN, P.; WILLHAUCK, G.; LINGENFELDER, I.; HEYNEN, M. Multi-resolution, object-oriented fuzzy analysis of remote sensing data for GIS-ready information. ISPRS Journal of Photogrammetry \& Remote Sensing. v. 58, p. 239-258. 2004. DOI: 10.1016/j.isprsjprs.2003.10.002

8. BISHOP, M. P.; JAMES, L. A.; SHRODER JR, J. F.; WALSH, S. J. Geospatial techonologies and digital geomorphological mapping: concepts, issues and research. Geomorphology. n. 137, p. 5-26, 2012. DOI: 10.1016/j.geomorph.2011.06.027

9. BORTOLINI, W.; SILVEIRA, C. T.; SILVEIRA, R. M. P. Emprego de técnicas geomorfométricas na identificação de padrões de relevo. Revista Raega - O Espaço Geográfico em Análise. v. 41 Temático Geomorfologia. p. 131-150. 2017. DOI: 10.5380/raega.v41i0.51724

10. BORTOLINI, W., SILVEIRA, C. T., SILVEIRA, R. M. P., SILVA, J. M. F. Técnicas Geomorfométricas para a identificação de padrões de relevo: aplicação nas Cartas Curitiba e Cerro Azul, Estado do Paraná. Revista do Departamento de Geografia. v. 36. 2018. p. 15-32. DOI: $10.11606 /$ rdg.v36i0.144285

11. CAMARGO, F. F.; FLORENZANO, T. G.; ALMEIDA, C. M.; OLIVEIRA, C. G. Abordagens cognitivas para a identificação de unidades geomorfológicas por meio de dados ASTER/Terra. Revista Brasileira de Geociências. v. 39. n. 2. p. $276-288$. 2009. ISSN: 0375-7536

12. CONRAD, O.; BECHTEL, B.; BOCK, M.; DIETRICH, H.; FISCHER, E.; GERLITZ, L.; WEHBERG, J.; WICHMANN, V.; BÖHNER, J. System for Automated Geoscientific Analyses (SAGA) v. 2.1.4, Geoscientific Model Development, 8, 19912007, 2015. DOI: 10.5194/gmd-8-1991-2015

13. COSTA, R. C. R.; BUSS, M. D.; ROSA, R. O. Relatório de geomorfologia do Projeto RADAM - Folha SG.22 Curitiba, Folha SG.21 Asunción e Folha SG.23 Iguape. v. 35. 1983.

14. D'OLEIRE-OLTMANNS, S.; EISANK, C.; BLASCHKE, T. An object-based worklow to extract landforms at multiple scales from two distinct data types. IEEE Geoscience and Remote Sensing Letters. v. 10, n. 4, p. 947-951. 2013. DOI: 10.1109/LGRS.2013.2254465 
15. DEKAVALLA, M.; ARGIALAS, D. Object-based classification of global undersea topography and geomorphological features from the SRTM30_PLUS data. Geomorphology. v. 288. p. 66-82. 2017. DOI: 10.1016/j.geomorph.2017.03.026

16. DIKAU, R. The application of a digital relief model to landform analysis. In: RAPER, J. F. (Ed.), Three Dimensional Applications in Geographical Information Systems. London: Taylor \& Francis,1989. p. 51-77.

17. DRAGUT, L.; CSILLIK, O.; EISANK, C.; TIEDE, D. Automated parameterization of multi-scale imagem segmentation on multiple layers. ISPRS Journal of Photogrammetry and Remote Sensing. v. 88, p. 119-127. 2014. DOI: 10.1016/j.isprsjprs.2013.11.018

18. DRAGUT, L.; BLASCHKE, T. Automated classification of landform elements using object-based analysis. Geomorphometry. v. 81. p. 330-344. 2006. DOI: 10.1016/j.geomorph.2006.04.013

19. DRAGUT, L.; EISANK, C. Object representations at multiple scales from digital elevation models. Geomorphology. v. 129. p. 183-189. 2011. DOI: 10.1016/j.geomorph.2011.03.003

20. DRAGUT, L.; EISANK, C. Automated object-based classification of topography from SRTM data. Geomorphology. v. 141. p. 21-33. 2012. DOI: 10.1016/j.geomorph.2011.12.001

21. DRAGUT, L.; TIEDE, D.; LEVICK, S. R. ESP: a tool to estimate scale parameter for multiresolution image segmentation of remotely sensed data. International Journal of Geographical Information Science. v. 24, n. 6, p. 859-871, 2010. DOI: $10.1080 / 13658810903174803$

22. EISANK, C.; SMITH, M.; HILLIER, J. Assessment of multiresolution segmentation for delimiting drumlins in digital elevations models. Geomophology. v. 214. p. 452-464. 2014. DOI: 10.1016/j.geomorph.2014.02.028

23. FALEIROS, F. M. Evolução de terrenos tectono-metamórficos da Serrania do Ribeira e Planalto Alto Turvo (SP, PR). 2008. Tese (Doutorado em Geoquímica e Geotectônica) - Programa de Pós-Graduação em Geoquímica e Geotectônica, Instituto de Geociências, Universidade de São Paulo, São Paulo. 306 p.

24. FIORI, A. P. Tectônica e estratigrafia do Grupo Açungui-PR. Boletim IG-USP, Sér.Cient. v. 3. p. 55-74, 1992. DOI: 10.11606/issn.2316-8986.v23i0p55-74

25. FIORI, A. P.; GASPAR, L. A. Considerações sobre a estratigrafia do Grupo Açungui (Proterozóico Superior), Paraná, Sul do Brasil. Bol. IG-USP, Sér. Cient., 24:1-19. 1993. DOI: 10.11606/issn.2316-8986.v24i0p1-19

26. GERÇEK, D.; TOPRAK, V.; STROBL, J. Object-based classification of landforms based on their local geometry and geomorphometric context. International Journal of Geographical Information Science. v. 25, n. 6, p. 1011-1023. 2011. DOI: $10.1080 / 13658816.2011 .558845$

27. GOMES, S.M.A; SILVEIRA, R.M.P; SILVEIRA, C.T. Aplicação de técnicas geomorfométricas para classificação de formas do relevo em Campo Largo, estado do Paraná - Brasil. RevistaGeografar, 13, 1, 75-97, 2018. DOI: 10.5380/geografar.v13i1.56463

28. HENGL, T. Finding the right pixel size. Computers \& Geosciences. 32, 1283-1298, 2006. DOI: 10.1016/j.cageo.2005.11.008

29. HENGL, T; MCMILLAN, R. A. Geomorphometry: A Key to Landscape Map and Modelling. In: HENGL, T.; REUTER, H. I. (eds.) Geomorphometry - Concepts, Software, Applications, Series Developments in Soil Science vol. 33, Amsterdam: Elsevier, pp. 433-460, 2009.

30. HORN, B. K. P. Hill shading and the reflectance map. Proceedings of the IEEE, n. 69, v.01, p. 14-47, 1981. DOI: 10.1109/PROC.1981.11918

31. HUTCHINSON, M. F. A new procedure for gridding elevation and stream line data with automatic removal of spurious pits. Journal of Hydrology, 106, p. 211-272, 1989. DOI: 10.1016/0022-1694(89)90073-5

32. IBGE - Instituto Brasileiro de Geografia e Estatística. Manual Técnico de Geomorfologia. $2^{a}$ ed. Rio de Janeiro: Instituto Brasileiro de Geografia e Estatística, 175 p., 2009. 
33. KAUL, P. F. T. O magmatismo na Serra do Mar e adjacências (sul do Brasil) no final do Proterozoico e seus condicionantes tectônicos. 1997. Tese (Doutorado em Geociências) - Instituto de Geociências, Universidade de São Paulo, São Paulo. 291 p.

34. LINDSAY, J. B. Whitebox GAT: A case study in geomorphometric analysis. Computers \& Geosciences, v. 95, p. 75-84, 2016. DOI: 10.1016/j.cageo.2016.07.003

35. LINDSAY, J. $\quad$ B. WhiteboxTools User $\quad$ Manual. $2019 . \quad$ Disponível: <https://jblindsay.github.io/wbt book/available tools/geomorphometric analysis.html\#EdgeDensity>

36. MINEROPAR - SERVIÇO GEOLÓGICO DO PARANÁ. Atlas geológico do estado Paraná. Minerais do Paraná, Curitiba, 2001.

37. OKA-FIORI, C., SANTOS, L.J.C., CANALI, N.E., FIORI, A.P., SILVEIRA, C.T., SILVA, J.M.F., ROSS, J.L.S. Atlas geomorfológico do estado do Paraná: Escala base 1:250.000 modelos reduzidos 1:500.000. Curitiba, Minerais do Paraná SA. - MINEROPAR; Universidade Federal do Paraná. Curitiba, 2006. 59p.

38. OLAYA, V. Basic Land-Surface Parameters. In: HENGL, T.; REUTER, H. I. (eds.) Geomorphometry - Concepts, Software, Applications, Series Developments in Soil Science vol. 33, Amsterdam: Elsevier, pp. 141-169, 2009.

39. OLIVEIRA, M. A. F.; MANIESI, V.; TEIXEIRA, W.; DAITX, E. C. Caracterização Isotópica de Metabasitos e Anfibolitos dos Grupos Açungui e Setuva na Porção Sul da Faixa Ribeira. Geol. USP Sér. Cient., São Paulo, v. 2, p. 161-170, dez 2002. DOI: 10.5327/S1519-874X2002000100013

40. PIKE, R. J. Geomorphometry - diversity in quantitative surface analysis. Progress in Physical Geography, v. 24. n.1, p. 1-20, 2000. DOI: 10.1177/030913330002400101

41. PIKE, R. J.; EVANS, I., HENGL, T. Geomorphometry: A BriefGuide. In: HENGL, T.; REUTER, H. I. (eds.) Geomorphometry - Concepts, Software, Applications, Series Developments in Soil Science vol. 33, Amsterdam: Elsevier, pp. 3-30, 2009.

42. RENNE, P. R.; DECKART K.; ERNESTO, M.; FÉRAUD G.; PICCIRILLO E. M. Age of the Ponta Grossa dike swarm (Brazil), and implications to Paraná flood volcanism. Earth and Planetary Science Letters, v. 144, p. 199-211, 1996. DOI: 10.1016/0012-821X(96)00155-0

43. ROSA FILHO, E. F.; GUARDA, M. J. Compartimentação hidrogeológica da Formação Capiru na região norte de CuritibaPR, Brasil. Águas Subterrâneas. , v. 22, n. 01, p. 67-74, 2008. DOI: 10.14295/ras.v22i1.17024

44. ROSS, J. S. Registro cartográfico dos fatos geomorfológicos e a questão da taxonomia do relevo. Revista do Departamento de Geografia, v. 6, p. 17-29, 1992. DOI: 10.7154/RDG.1992.0006.0002

45. ROSS, J. L. S.; MOROZ, I. C. Mapa geomorfológico do estado de São Paulo: Escala 1:500.000. Volume I e Volume II. Depto. Geografia FFLHC-USP, IPT e FAPESP, 1997.

46. SALAMUNI, E.; SALAMUNI, R.; EBERT, H. D. Contribuição à geologia da bacia sedimentar de Curitiba (PR). Boletim Paranaense de Geociências. n. 47, p. 123-142, 1999. ISSN: 0067-964X

47. SALAMUNI, E. EBERT, H. D.; HASUI, Y. Morfotectonica da bacia sedimentar de Curitiba. Revista Brasileira de Geociências. v. 34, n. 4, p. 469-478, 2004. ISSN: 0375-7536

48. SALAMUNI, E.; NASCIMENTO, E. R.; SILVA, P. H. K.; OKA-FIORI, C. Geomorfologia do município de Curitiba-PR. Revista Brasileira de Geomorfologia. v. 14, n. 4, p. 327-341, 2013. DOI: 10.20502/rbg.v14i4.428

49. SANTOS, L.J.C.; OKA-FIORI, C.; CANALI, N.E.; FIORI, A.P.; SILVEIRA, C.T.; SILVA, J.M.F.; ROSS, J.L.S. Mapeamento geomorfológico do Estado do Paraná. Revista Brasileira de Geomorfologia, n. 2, p. 3-12, 2006. DOI: 10.20502/rbg.v7i2.74

50. SILVEIRA, C. T.; SILVEIRA, R. M. P.; BORTOLINI, W.; ALMEIDA, V. P. Método para a identificação de padrões de formas de relevo com uso da modelagem digital do terreno: emprego na ampliação da escala do mapeamento geomorfológico do Paraná - Brasil. (inédito). 
51. STROBL, J. Segmentation-based Terrain Classification. In: ZHOU, Q.; LEES, B.; TANG, G. (eds.). Advances in Digital Terrain Analysis. Series: Lecture Notes in Geoinformation and Cartography. Berlim: Springer-Verlag, 2008.

52. TEDESCO, A.; ANTUNES, A. F. B.; OLIANI, L. O. Detecção de formação erosiva (voçoroca) por meio de classificação hierárquica e por árvore de decisão. Boletim de Ciências Geodésicas, sec. Artigos, Curitiba, v. 20, no 4, p.1005-1026, outdez, 2014. DOI: 10.1590/S1982-21702014000400055

53. VAN NIERKERK, A. A comparasion of land unit delineation techiniques for land evaluation in the Western Cape, South Africa. Land Use Policy. v. 27. p. 937-947. 2010. DOI: 10.1016/j.landusepol.2009.12.007

54. VERHAGEN, P.; DRAGUT, L. Object-based landform delieation and classification from DEMs for archeological predictive mapping. Journal of Archaeological Science. v. 30. p. 698-703. 2012. DOI: 10.1016/j.jas.2011.11.001

55. WEISS, A. Topographic Position and Landforms Analysis. Poster presentation, ESRI User Conference, San Diego, CA, 2001.

56. WILLHAUCK, G. Comparison of object oriented classification techniques and standard image analysis for the use of change detection between SPOT multispectral satellite images and aerial photos. ISPRS, v. XXXIII, Amsterdam, 2000.

57. WILSON, J. P.; GALLANT, J. C. (eds.). Terrain analysis: principles and applications. New York: John Wiley \& Sons, p.1$27,2000$.

58. WILSON, J. P. Digital terrain modelling. Geomorphology, 137, p.107-121, 2012. DOI: 10.1016/j.geomorph.2011.03.012

59. WOOD, J. The geomorphological characterisation of digital elevation models. Leicester, UK, 1996. 185p. PhD Thesis University of Leicester. Disponivel em: http://www.soi.city.ac.uk/ jwo/phd.

Esta obra está licenciada com uma Licença Creative Commons Atribuição 4.0 Internacional (http://creativecommons.org/licenses/by/4.0/) - CC BY. Esta licença permite que outros distribuam, remixem, adaptem e criem a partir do seu trabalho, mesmo para fins comerciais, desde que lhe atribuam o devido crédito pela criação original. 